\title{
Article \\ Adsorption Characteristics of Pristine and Magnetic Olive Stones Biochar with Respect to Clofazimine
}

\author{
Marwa El-Azazy *(D), Iman Nabil, Siham S. Hassan and Ahmed S. El-Shafie \\ Department of Chemistry and Earth Sciences, College of Arts and Sciences, Qatar University, Doha 2713, Qatar; \\ ia1703713@student.qu.edu.qa (I.N.); s.hersi@qu.edu.qa (S.S.H.); aelshafie@qu.edu.qa (A.S.E.-S.) \\ * Correspondence: marwasaid@qu.edu.qa
}

check for updates

Citation: El-Azazy, M.; Nabil, I.; Hassan, S.S.; El-Shafie, A.S.

Adsorption Characteristics of Pristine and Magnetic Olive Stones Biochar with Respect to Clofazimine. Nanomaterials 2021, 11, 963. https://doi.org/10.3390/ nano11040963

Academic Editor: Lidija Curković

Received: 13 March 2021

Accepted: 7 April 2021

Published: 9 April 2021

Publisher's Note: MDPI stays neutral with regard to jurisdictional claims in published maps and institutional affiliations.

Copyright: (c) 2021 by the authors. Licensee MDPI, Basel, Switzerland. This article is an open access article distributed under the terms and conditions of the Creative Commons Attribution (CC BY) license (https:/ / creativecommons.org/licenses/by/ $4.0 /)$.

\begin{abstract}
Olive stone biochars (OSBC), both pristine and following magnetization (MAG-OSBC), were utilized as eco-friendly and cost-effective sorbents for the antituberculosis, clofazimine (CLOF). Morphologies, textures, surface functionalities, and thermal stabilities of both adsorbents were explored using SEM, EDX, TEM, BET, FT-IR, Raman, XRD and TGA analyses. SEM analysis showed meso- and macroporous surfaces. BET data showed that the MAG-OSBC possesses a larger surface area $\left(33.82 \mathrm{~m}^{2} / \mathrm{g}\right)$ and pore volume. Batch adsorption studies were conducted following the experimental scenario of Box-Behnken (BB) design. The adsorption efficiency of both adsorbents was evaluated in terms of the $\%$ removal $(\% \mathrm{R})$ and the sorption capacity $\left(q_{e}, \mathrm{mg} / \mathrm{g}\right)$. Dependent variables (\%R and $q_{e}$ ) were maximized as a function of four factors: $\mathrm{pH}$, sorbent dose (AD), the concentration of CLOF ([CLOF]), and contact time (CT). A \% of $98.10 \%$ and $98.61 \%$ could be obtained using OSBC and MAG-OSBC, respectively. Equilibrium studies indicated that both Langmuir and Freundlich models were perfectly fit for adsorption of CLOF. Maximum adsorption capacity $\left(q_{\max }\right)$ of 174.03 $\mathrm{mg} / \mathrm{g}$ was obtained using MAG-OSBC. Adsorption kinetics could be best illustrated using the pseudo-second-order (PSO) model. The adsorption-desorption studies showed that both adsorbents could be restored with the adsorption efficiency being conserved up to $92 \%$ after the sixth cycles.
\end{abstract}

Keywords: clofazimine; green adsorbent; wastewater; olive stones biochar; magnetized biochar; box-behnken design

\section{Introduction}

Pharmaceutically active compounds (PhACs) and pharmaceutical and personal care products (PPCPs) represent a significant category of emergent pollutants that have enticed the attention of the scientific community, health authorities, and the public. With the increased health awareness, the daily use of PhACs and PPCPs is becoming indispensable. The 2017 report issued by the Organization for Economic Cooperation and Development has mentioned that the expenditure on wholesale pharmaceuticals per capita averaged 564 \$/person in the USA and that 75\% of this figure was for prescription drugs. Possessing disparate chemical structures, most such compounds cannot be removed effectively by conventional wastewater treatment technologies. Considering their hazardous impacts not only on human and animal health but on environmental safety as well, the existence of PhACs and PPCPs (in water, food, etc.) represents a challenge [1-3].

Clofazimine (CLOF), a member of the riminophenazine family, is an antimicrobial drug that is commonly used to treat leprosy and drug-resistant tuberculosis (TB). As per the WHO (World Health Organization), CLOF is listed as one of the essential medicines (safest and most effective list of medications) [4,5]. Recent investigations following the COVID-19 pandemic showed that CLOF and thanks to its remarkable anti-inflammatory and immunomodulatory effects, could be used as a therapy in severe COVID-19 cases [6-9]. Scheme 1 shows the relevant physicochemical data of CLOF [10]. Before the current pandemic, TB was classified as one of the leading causes of death in the world. In 2013, 1.5 million TB-associated deaths 
were reported. One of the major reasons behind such a crisis is the emergence of drug-resistant TB [11,12]. By and large, these numbers are alarming. On one hand, the existence of these antimicrobials in wastewater may lead to the appearance of antibiotic-resistant strains of TB $[13,14]$. On the other hand, a literature survey shows little effort being reported to remove the anti-TB drugs from wastewater. Efforts were mainly focused on using advanced oxidation processes (AOPs), electro-Fenton and photoelectro-Fenton technologies $[15,16]$.<smiles>CC(C)N=c1cc2n(-c3ccc(Cl)cc3)c3ccccc3nc-2cc1Nc1ccc(Cl)cc1</smiles>

Scheme 1. Chemical structure of clofazimine (CLOF). Chemical Formula: $\mathrm{C}_{27} \mathrm{H}_{22} \mathrm{Cl}_{2} \mathrm{~N}_{4}(473.4 \mathrm{~g} / \mathrm{mol})$; IUPAC Name: (N,5-bis(4-chlorophenyl)-3-propan-2-yliminophenazin-2-amine; $\mathrm{pK}_{\mathrm{a} 1}: 9.29, \mathrm{pK}_{\mathrm{a} 2}: 2.31$ [10].

Possessing contemporary surface properties, carbon-based materials (CBMs) and especially those obtained from a natural precursor (recycled agro-wastes) are among the most widely investigated adsorbents [2]. Applications included the removal of organics, e.g., PhACs, pesticides, dyes, etc. [13-22], as well as inorganics [23,24]. By and large, biochars obtained from agro-wastes possess high surface area, unique pore size and pore distribution, in addition to being cost-effective. Moreover, with their lignocellulosic origin, the existence of various functional groups on their surface and the potential for further functionalization facilitate a strong interaction with the target pollutant.

Yet, the difficulty of separating the powdered biochar from the environmental medium hinders the application of these adsorbents on a wide scale and may lead to secondary pollution. Magnetization of carbonaceous wastes helps to overcome this problem. The introduction of the magnetite (or other transition metals and their oxides) creates a separable adsorbent. Moreover, the presence of magnetic nanoparticles with their small particle size, high surface area: volume ratio, fast adsorption kinetics, and potential for recovery and regeneration help to create a unique adsorbent [14,25-27].

Olive oil production is a well-established industry. As per the International Olive Council, Spain, as a major producer of olive oil, produces around 625,600 tons/year [28]. The Food and Agriculture Organization (FAO) data report of 2019 shows 21 million tons annual production of olives worldwide [29]. Yet, this industry and with the production of various byproducts are facing serious sustainability problems. While only $20 \%$ of the original olive mass is converted into olive oil, the fate of $\sim 50 \%$ is olive mill wastewater, and $\sim 30 \%$ will be a solid waste (pulp and pit) [30]. These byproducts represent a burden on the environment if not properly managed. Though an escalating interest in the use of the biochar of olive pits can be glimpsed in the literature, yet their use as a cost-effective adsorbent, especially for the removal of the PhACs, remains underestimated. Table 1 shows a summary of the approaches that have used biochar of olive stones for the treatment of pharmaceutical wastewater as well as other organics [31-37]. As shown in Table 1, most of the reported approaches, if not all, involve the removal of $\mathrm{PhACs}$, dyes and pesticides using pristine or chemically modified biochar of olive stones and follow a univariate-based approach for investigating the process variables. This approach is not only consuming time and resources but also does not preserve the method's greenness. 
Table 1. Reported applications of the biochars obtained from olive stones for the removal of pharmaceutically active compounds (PhACs) and other organics.

\begin{tabular}{|c|c|c|c|c|c|c|c|c|}
\hline Adsorbent & Adsorbate & Analytical Approach & Kinetic Model & Isotherm Model & Surface Area $\left(\mathrm{m}^{2} / \mathrm{g}\right)$ & $q_{\max }(\mathrm{mg} / \mathrm{g})$ & $\% \mathbf{R}$ & Ref. \\
\hline $\begin{array}{l}\text { Olive stone biochar } \\
\text { (OSBC) } \\
\text { Magnetic olive stone } \\
\text { biochar (MAG-OSBC) }\end{array}$ & $\begin{array}{l}\text { Clofazimine } \\
\text { (CLOF) }\end{array}$ & $\begin{array}{l}\text { Batch adsorption, } \\
\text { multivariate analysis } \\
\text { (Box-Behnken) design }\end{array}$ & * PSO & $\begin{array}{l}\text { Langmuir and } \\
\text { Freundlich }\end{array}$ & $\begin{array}{l}22.20 \\
33.82\end{array}$ & $\begin{array}{l}137.90 \\
174.03\end{array}$ & $\begin{array}{l}98.10 \% \\
98.61 \%\end{array}$ & Current study \\
\hline $\begin{array}{l}\text { Acid treated olive } \\
\text { stones (ATOS) }\end{array}$ & Drin pesticides & $\begin{array}{l}\text { Batch adsorption, } \\
\text { univariate analysis }\end{array}$ & * PSO & Freundlich & 479 & $19.54-43.71$ & $>90 \%$ & [31] \\
\hline $\begin{array}{l}\text { Olive stones (OS) and } \\
\text { activated carbon olive } \\
\text { stones (OSAC) }\end{array}$ & $\begin{array}{l}\text { Methylene blue } \\
\text { (MB) }\end{array}$ & $\begin{array}{l}\text { Batch adsorption, } \\
\text { univariate analysis }\end{array}$ & ${ }^{*} \mathrm{PSO}$ & Temkin & ${ }^{* *} \mathrm{NS}$ & $\begin{array}{c}\text { OSAC: } 16.2 \text { OS: } \\
12.9\end{array}$ & $\begin{array}{l}\text { OSAC: } 94 \% \\
\text { OS: } 70 \%\end{array}$ & {$[32]$} \\
\hline $\begin{array}{l}\text { Zinc } \\
\text { chloride-activated } \\
\text { carbon prepared from } \\
\text { olive stone (ACOS) }\end{array}$ & $\begin{array}{l}\text { Remazol red B } \\
\text { (RRB) }\end{array}$ & $\begin{array}{l}\text { Batch } \\
\text { adsorption, univariate } \\
\text { analysis }\end{array}$ & * PSO & Langmuir & $\begin{array}{c}\text { ACOS: } 3 \\
\mathrm{ZnCl}_{2} \text {-activated: } \\
58-790\end{array}$ & ACOS: 9.33 & ACOS: 75\% & [33] \\
\hline $\begin{array}{l}\text { Olive stone biomass } \\
\text { (OS) }\end{array}$ & $\begin{array}{l}\text { Alizarin red S } \\
\text { (ARS) } \\
\text { Methylene blue } \\
\text { (MB) }\end{array}$ & $\begin{array}{l}\text { Batch adsorption, } \\
\text { univariate analysis }\end{array}$ & * PSO & $\begin{array}{l}\text { Redlich- } \\
\text { Peterson }\end{array}$ & 0.16 & $\begin{array}{l}\text { ARS: } 16.10 \\
\text { MB: } 13.20\end{array}$ & $\begin{array}{l}\text { ARS: } 85 \% \\
\text { MB: } 75 \%\end{array}$ & {$[34]$} \\
\hline $\begin{array}{l}\text { Magnetic adsorbent } \\
\text { from the olive kernel } \\
\text { (MA-OK) }\end{array}$ & $\begin{array}{l}\text { Amoxicillin } \\
(\mathrm{AMX})\end{array}$ & $\begin{array}{l}\text { Batch adsorption, } \\
\text { univariate analysis }\end{array}$ & * PSO & Langmuir & 2188.0 & 238.1 & ${ }^{* *} \mathrm{NS}$ & [35] \\
\hline $\begin{array}{l}\text { Olive stones } \\
\text { chemically activated } \\
\text { with phosphoric acid }\end{array}$ & Paracetamol (PA) & $\begin{array}{l}\text { Batch and small-scale } \\
\text { column studies, } \\
\text { univariate analysis }\end{array}$ & Vermeulen & Langmuir & 1000 & 100 & $* *$ NS & {$[36]$} \\
\hline $\begin{array}{l}\text { Activated carbon from } \\
\text { olive stones (ACOS) }\end{array}$ & $\begin{array}{l}\text { Diclofenac sodium } \\
\text { (DCF) }\end{array}$ & $\begin{array}{l}\text { Batch adsorption, } \\
\text { univariate analysis }\end{array}$ & ${ }^{*} \mathrm{PSO}$ & BET & 83.72 & 11.0071 & $* *$ NS & [37] \\
\hline
\end{tabular}


The current investigation targets developing an economic adsorbent and an ecostructured adsorption approach. The goal will be set to preserve the adsorbent's costeffectiveness and the method of greenness. Consequently, the variables that influence the adsorption of CLOF will be optimized. Box-Behnken (BB) design will be, therefore, utilized to tune the process variables; $\mathrm{pH}$, the dose of the biochar (AD), contact time (CT) and concentration of CLOF [38,39]. Two adsorbents will be prepared: pristine olive stone biochar (OSBC) and magnetic biochar (MAG-OSBC). The impact of the aforementioned variables on the performance of both adsorbents will be assessed. The novelty of the current endeavor, therefore, stems from being the first report on using waste-derived materials via an eco-structured approach for the removal of CFZ. In the same itinerary, and since the adsorbent recycling and reuse are essential features from the industrial point-of-view, the reusability and regeneration of both adsorbents will be attested.

\section{Materials and Methods}

\subsection{Materials, Equipment, and Software}

Chemicals used in this study including sodium hydroxide, hydrochloric acid, acetic acid, sodium chloride, nitric acid, sulfuric acid, sodium carbonate, ethanol, ferrous ammonium sulfate hexahydrate $\left(\mathrm{Fe}\left(\mathrm{NH}_{4}\right)_{2}\left(\mathrm{SO}_{4}\right)_{2} \cdot 6 \mathrm{H}_{2} \mathrm{O}\right)$, and ammonium iron (III) sulfate dodecahydrate $\left(\mathrm{NH}_{4} \mathrm{Fe}\left(\mathrm{SO}_{4}\right)_{2} \cdot 12 \mathrm{H}_{2} \mathrm{O}\right)$ were purchased from Sigma-Aldrich (St. Louis, MO, USA). Clofazimine (CLOF) was purchased from Biosynth ${ }^{\circledR}$ Carbosynth Ltd. (Compton, Berkshire, UK). Olives were purchased from local supermarkets in Doha, Qatar. Stones were dried in an oven (Memmert, GmbH + Co. KG, Schwabach, Germany) and burnt in the Thermolyne ${ }^{\mathrm{TM}}$ furnace (Barnstead, Dubuque, IA, USA). Millipore-Q water system was used to obtain the deionized water used throughout this study. To prepare the CLOF stock solution (100 ppm), the drug was dissolved using few drops of acetic acid, and the volume was made up to the mark using deionized water. The $\mathrm{pH}$ of water in which the adsorbents were suspended was adjusted using either $0.1 \mathrm{M} \mathrm{NaOH}$ or $0.1 \mathrm{M} \mathrm{HCl}$. The $\mathrm{pH}$ measurements were made using a Vernier LabQuest $\mathrm{pH}$ meter. Concentrations of CLOF before and after adsorption were measured using a UV-vis spectrophotometer (Agilent diode-array, Agilent, Santa Clara, CA, USA) with $10 \mathrm{~mm}$ matched quartz cuvettes. A Millex syringe filter (nylon, nonsterile, $0.45 \mu \mathrm{m}$ ) was used to filter solutions.

To determine the functional groups on the surface of the adsorbent, FT-IR spectroscopy (FT-IR, PerkinElmer, Shelton, CT, USA) was utilized. The surface morphology of both adsorbents was examined using a scanning electron microscope (SEM, FEI, Quanta 200, Thermo Scientific, Waltham, MA, USA) equipped with an energy-dispersive X-ray spectrometer (EDX). The latter was used to identify the elemental composition of both adsorbents. Raman spectroscopy was used to study the nature of the carbonaceous material (Thermo Scientific, Waltham, MA, USA). Transmission electron microscope (TEM, FEI, TECNAI G2 TEM, TF20) was used for microstructural characterization of OSBC-MAG. To further study the surface characteristics, pore size, surface area and volume were measured using a Micrometrics ASAP2020 accelerated surface area and porosimetry system. Degassing of samples was conducted, followed by the $\mathrm{N}_{2}$ adsorption-desorption study. To calculate the surface area, the isotherms measured at $77 \mathrm{~K}$ were used along with applying the Brunauer-Emmett-Teller (BET) equation. To find the pore volume, $t$-plots were used with Barrett-Joyner-Halenda (BJH) equations. The X-ray diffraction pattern (XRD) was explored on an X-ray diffractometer (X'Pert-Pro MPD, PANalytical Co., Almelo, the Netherlands) using $\mathrm{Cu} \mathrm{K} \alpha \mathrm{X}$-ray source $\left(\lambda=1.540598 \AA\right.$ ) operated over a $2 \mathrm{~h}$ range of $5-80^{\circ}(2 \theta)$.

Minitab ${ }^{\circledR} 19$ software was purchased from Minitab Inc. (State College, PA, USA) and was used to construct and analyze the BB design.

\subsection{Preparation of Olive Stone Biochar (OSBC)}

Olive stones were removed from olives and were washed five times with tap water first, followed by the other five times using distilled water. After washing, the clean stones were placed in the oven at $80{ }^{\circ} \mathrm{C}$ for three consecutive days. Following this treatment, 
portions of the olive stones were placed in crucibles and left in the oven at $500{ }^{\circ} \mathrm{C}$ for $1 \mathrm{~h}$. The stones were crushed using an agate mortar and a pestle, finely divided, and then sieved using an $0.125 \mathrm{~mm}$ sieve, and the obtained powder was placed in a sealed bottle and kept for further use.

\subsection{Preparation of Magnetic Olive Stone Biochar (MAG-OSBC)}

For magnetite $\left(\mathrm{Fe}_{3} \mathrm{O}_{4}\right)$ preparation, the co-precipitation method was utilized $[14,40]$ with minor modifications. A $200 \mathrm{~mL}$ of $0.1 \mathrm{M} \mathrm{Fe}^{3+}$ solution was mixed with a $100 \mathrm{~mL}$ of $0.1 \mathrm{M}$ $\mathrm{Fe}^{2+}$ solution. An amount of $10.0 \mathrm{~g}$ of the sieved OSBC was suspended in the $\mathrm{Fe}^{3+} / \mathrm{Fe}^{2+}$ mixture. The suspension was stirred for $2 \mathrm{~h}$, and $1 \mathrm{M} \mathrm{NaOH}$ solution was added dropwise to $\mathrm{pH} \sim 12$. The mixture was left at room temperature for $30 \mathrm{~min}$ and later was washed with distilled water and then ethanol (five times each), and an external magnet was used to separate the MAG-OSBC. Each step was accompanied by separation using the magnet followed by decantation. Following these washing cycles, the product was dried in the oven at $80{ }^{\circ} \mathrm{C}$ overnight. The dried product was kept in sealed bottles for further use.

\subsection{Determination of the Point-of-Zero-Charge $\left(p H_{P Z C}\right)$}

For the determination of $\mathrm{pH}_{\mathrm{PZC}}$, equal amounts $(1.0 \mathrm{~g})$ of either OSBC or MAG-OSBC were added to a set of seven flasks, each containing $50 \mathrm{~mL}$ of $0.01 \mathrm{M} \mathrm{NaCl}$. The $\mathrm{pH}$ in each flask was adjusted to values between 3.0 to $9.0 \pm 0.2$ using either $0.1 \mathrm{M} \mathrm{HCl}$ or $0.1 \mathrm{M} \mathrm{NaOH}$. Samples were left to equilibrate for $48 \mathrm{~h}$ in the automatic shaker at $150 \mathrm{rpm}$ before measuring the final $\mathrm{pH}$, and an intersection point of the curve $\left(\mathrm{pH}_{\text {final }}\right.$ versus $\left.\mathrm{pH}_{\text {initial }}\right)$ is the $\mathrm{pH}_{\text {PZC }}$ value [17].

\subsection{Batch Adsorption Experiments (Response Surface Design)}

In the current investigation, Box-Behnken (BB) design was used to optimize the adsorption process variables for each of the two tested adsorbents. Four factors were tested: $\mathrm{pH}$, [CLOF], $\mathrm{AD}$, and CT, Table 2 (lower bound is -1 , while the upper bound is +1 ). The objective was to maximize the percentage removal $(\% \mathrm{R})$ and the adsorption capacity $\left(q_{e}, \mathrm{mg} / \mathrm{g}\right)$. These two parameters were used to assess the adsorptive power of the two adsorbents and were calculated using Equations (1) and (2). The design output involved 27 runs comprising 3 central points $(\mathrm{Ct} \mathrm{Pt})$. The design was conducted over 3 blocks, Table 3.

Table 2. Dependent and independent variables together with their levels.

\begin{tabular}{cccc}
\hline Factors & $\mathbf{- 1}$ & $\mathbf{0}$ & $\mathbf{+ 1}$ \\
\hline $\mathrm{pH}(\mathrm{A}, \mathrm{pH}$ unit) & 3.0 & 6.0 & 9.0 \\
Adsorbent dose (AD, B, mg/13 mL) & 30.0 & 75.0 & 120.0 \\
Initial drug concentration ([CLOF], C, ppm) & 10.0 & 35.0 & 60.0 \\
Contact time (CT, D, min) & 10.0 & 50.0 & 90.0 \\
Dependent variables & Percentage removal $(\% \mathrm{R})$ & \\
\hline
\end{tabular}

$$
\begin{gathered}
(\% \mathrm{R})=\frac{C_{0}-C_{e}}{C_{0}} \times 100 \% \\
\left(q_{e}\right)=\frac{C_{0}-C_{e}}{\mathrm{~W}} \mathrm{~V}
\end{gathered}
$$

where $C_{0}(\mathrm{ppm})$ symbolizes the initial concentration of [CLOF] solution, $C_{e}$ is the concentration of the [CLOF] solution at equilibrium, $\mathrm{V}$ is the volume of the solution $(\mathrm{L})$, and $\mathrm{W}$ is the weight of the adsorbent used $(\mathrm{g})$. 
Table 3. Experimental setup using Box-Behnken (BB) design. Observed and predicted values for \%R and $q_{e}$, as well as the relative error (RE), are shown.

\begin{tabular}{|c|c|c|c|c|c|c|c|c|c|c|c|c|c|c|c|c|}
\hline \multicolumn{5}{|c|}{ Variables } & \multicolumn{6}{|c|}{ OSBC } & \multicolumn{6}{|c|}{ MAG-OSBC } \\
\hline $\begin{array}{l}\text { Trial } \\
\text { No }\end{array}$ & $\mathrm{AD}$ & [CLOF] & CT & $\mathrm{pH}$ & $\begin{array}{c}\% \mathbf{R} \\
\text { Obs.* }\end{array}$ & $\begin{array}{c}\% R \\
\text { Pred.** }\end{array}$ & $\mathrm{RE}^{* * *}$ & $\begin{array}{c}q_{e} \\
\text { Obs.* }\end{array}$ & $\begin{array}{c}q_{e} \\
\text { Pred.** }\end{array}$ & $\mathbf{R E} * * *$ & $\begin{array}{c}\% \mathbf{R} \\
\text { Obs.* }\end{array}$ & $\begin{array}{c}\% \mathbf{R} \\
\text { Pred.** }\end{array}$ & $\mathbf{R E}^{* * *}$ & $\begin{array}{c}q_{e} \\
\text { Obs.* }\end{array}$ & $\begin{array}{c}q_{e} \\
\text { Pred.** }\end{array}$ & $\mathbf{R E} * * *$ \\
\hline 01 & $30(-)$ & $35(0)$ & $50(0)$ & $3(-)$ & 97.81 & 98.56 & 0.01 & 12.67 & 11.29 & 0.12 & 50.27 & 48.14 & 0.04 & 7.55 & 7.36 & 0.03 \\
\hline 02 & $120(+)$ & $60(+)$ & $50(0)$ & $6(0)$ & 44.37 & 44.85 & 0.01 & 2.88 & 2.84 & 0.02 & 71.18 & 71.80 & 0.01 & 4.99 & 4.98 & 0.00 \\
\hline 03 & $30(-)$ & $10(-)$ & $50(0)$ & $6(0)$ & 27.12 & 31.65 & 0.14 & 1.57 & 1.97 & 0.20 & 56.21 & 55.44 & 0.01 & 2.42 & 2.35 & 0.03 \\
\hline 04 & $75(0)$ & $35(0)$ & $10(-)$ & $3(-)$ & 94.11 & 93.69 & 0.00 & 5.69 & 5.72 & 0.00 & 47.21 & 46.81 & 0.01 & 2.85 & 2.80 & 0.02 \\
\hline 05 & $30(-)$ & $35(0)$ & $50(0)$ & $9(+)$ & 70.79 & 67.74 & 0.05 & 7.85 & 7.57 & 0.04 & 62.67 & 59.93 & 0.05 & 9.02 & 8.51 & 0.06 \\
\hline 06 & $120(+)$ & $35(0)$ & $90(+)$ & $6(0)$ & 81.70 & 75.15 & 0.09 & 1.85 & 1.42 & 0.30 & 77.45 & 73.51 & 0.05 & 2.94 & 2.78 & 0.06 \\
\hline 07 & $75(0)$ & $10(-)$ & $90(+)$ & $6(0)$ & 38.74 & 43.18 & 0.10 & 0.67 & -0.12 & 6.59 & 86.62 & 83.65 & 0.04 & 1.50 & 1.44 & 0.04 \\
\hline 08 & $30(-)$ & $35(0)$ & $10(-)$ & $6(0)$ & 32.49 & 33.34 & 0.03 & 5.29 & 5.93 & 0.11 & 27.12 & 26.95 & 0.01 & 4.44 & 4.52 & 0.02 \\
\hline 09 & $75(0)$ & $10(-)$ & $10(-)$ & $6(0)$ & 52.30 & 51.21 & 0.02 & 0.90 & 0.11 & 7.22 & 61.61 & 58.43 & 0.05 & 1.07 & 0.99 & 0.08 \\
\hline 10 & $120(+)$ & $35(0)$ & $10(-)$ & $6(0)$ & 42.22 & 47.57 & 0.11 & 2.08 & 2.14 & 0.03 & 54.80 & 52.27 & 0.05 & 2.07 & 2.03 & 0.02 \\
\hline 11 & $120(+)$ & $10(-)$ & $50(0)$ & $6(0)$ & 82.68 & 82.98 & 0.00 & 0.89 & 1.65 & 0.46 & 98.61 & 100.80 & 0.02 & 1.12 & 1.14 & 0.02 \\
\hline 12 & $75(0)$ & $10(-)$ & $50(0)$ & $3(-)$ & 92.12 & 86.68 & 0.06 & 1.59 & 1.84 & 0.13 & 97.00 & 94.37 & 0.03 & 1.67 & 1.63 & 0.03 \\
\hline 13 & $75(0)$ & $60(+)$ & $50(0)$ & $3(-)$ & 97.81 & 96.47 & 0.01 & 10.14 & 10.16 & 0.00 & 84.15 & 82.38 & 0.02 & 9.22 & 8.91 & 0.03 \\
\hline 14 & $75(0)$ & $35(0)$ & $50(0)$ & $6(0)$ & 80.47 & 81.49 & 0.01 & 4.88 & 4.96 & 0.02 & 89.37 & 91.08 & 0.02 & 5.42 & 5.58 & 0.03 \\
\hline 15 & $75(0)$ & $35(0)$ & $50(0)$ & $6(0)$ & 79.71 & 81.49 & 0.02 & 4.83 & 4.96 & 0.03 & 88.00 & 91.08 & 0.03 & 5.27 & 5.58 & 0.06 \\
\hline 16 & $75(0)$ & $10(-)$ & $50(0)$ & $9(+)$ & 82.49 & 79.75 & 0.03 & 1.43 & 1.61 & 0.11 & 91.65 & 92.60 & 0.01 & 1.59 & 1.67 & 0.05 \\
\hline 18 & $120(+)$ & $35(0)$ & $50(0)$ & $9(+)$ & 96.74 & 95.04 & 0.02 & 3.66 & 3.61 & 0.01 & 72.18 & 72.47 & 0.00 & 2.96 & 2.92 & 0.02 \\
\hline 19 & $120(+)$ & $35(0)$ & $50(0)$ & $3(-)$ & 97.61 & 99.72 & 0.02 & 3.69 & 3.41 & 0.08 & 95.99 & 96.78 & 0.01 & 3.63 & 3.70 & 0.02 \\
\hline 20 & $75(0)$ & $60(+)$ & $90(+)$ & $6(0)$ & 77.62 & 77.76 & 0.00 & 8.07 & 8.31 & 0.03 & 69.11 & 70.30 & 0.02 & 7.18 & 7.47 & 0.04 \\
\hline 21 & $30(-)$ & $35(0)$ & $90(+)$ & $6(0)$ & 68.74 & 60.93 & 0.13 & 9.32 & 9.47 & 0.02 & 46.46 & 48.19 & 0.04 & 7.02 & 7.27 & 0.03 \\
\hline 22 & $75(0)$ & $60(+)$ & $50(0)$ & $9(+)$ & 66.53 & 67.9 & 0.02 & 6.92 & 6.88 & 0.01 & 73.26 & 74.75 & 0.02 & 7.59 & 7.93 & 0.04 \\
\hline 23 & $75(0)$ & $60(+)$ & $10(-)$ & $6(0)$ & 19.95 & 14.57 & 0.37 & 5.03 & 5.26 & 0.04 & 45.76 & 46.11 & 0.01 & 4.96 & 4.96 & 0.00 \\
\hline 24 & $75(0)$ & $35(0)$ & $90(+)$ & $3(-)$ & 80.02 & 84.35 & 0.05 & 4.85 & 5.35 & 0.09 & 82.13 & 85.35 & 0.04 & 4.98 & 5.15 & 0.03 \\
\hline 25 & $30(-)$ & $60(+)$ & $50(0)$ & $6(0)$ & 63.00 & 67.72 & 0.07 & 14.77 & 14.36 & 0.03 & 53.65 & 54.72 & 0.02 & 13.95 & 14.01 & 0.00 \\
\hline 26 & $75(0)$ & $35(0)$ & $50(0)$ & $6(0)$ & 84.30 & 81.49 & 0.03 & 4.82 & 4.96 & 0.03 & 90.30 & 91.08 & 0.01 & 5.60 & 5.58 & 0.00 \\
\hline 27 & $75(0)$ & $35(0)$ & $90(+)$ & $9(+)$ & 98.10 & 103.52 & 0.05 & 5.05 & 5.38 & 0.06 & 62.70 & 66.08 & 0.05 & 3.80 & 3.97 & 0.04 \\
\hline
\end{tabular}

* Obs.: observed readings; ${ }^{* *}$ Pred.: predicted readings; ${ }^{* * *} \mathrm{RE}=\mid($ true value - observed value) $\mid /$ true value. 
Equation (3) will be fitted to the data shown in Table 3, and the output will be the regression models that relate the measured response(s) to the input variables.

$$
Y=b_{1}+\sum_{i=1}^{n} b_{i} \cdot X_{i}+\sum_{i=1}^{n} b_{i i} \cdot X_{i}^{2}+\sum_{i=1}^{n-1} \cdot \sum_{j=i+1}^{n} b_{i j} X_{j} \cdot X_{i}+e
$$

where $Y$ is the measured response(s), \%R and $q_{e}(\mathrm{mg} / \mathrm{g}), e$ is the error, and $X_{i}, X_{j}$ are the input variables. The coefficients $b_{i}, b_{i i}, \ldots b_{i j}$ will be determined from the regression equations.

\subsection{Equilibrium and Kinetic Studies}

For equilibrium studies, a stock solution of $500 \mathrm{ppm}$ CLOF was prepared. Further dilutions (5-400 ppm) were prepared in deionized water, and the $\mathrm{pH}$ was tuned to $\mathrm{pH} 3.00 \pm 0.20$ using $0.1 \mathrm{M} \mathrm{HCl}$ and $0.1 \mathrm{M} \mathrm{NaOH}$. An amount of $0.100 \pm 0.005 \mathrm{~g}$ of either adsorbent was added to $13 \mathrm{~mL}$ of the previously prepared solution. The prepared suspensions were placed in the automatic shaker for an equilibrium time of $24 \mathrm{~h}$ at $150 \mathrm{rpm}$. Solutions were then filtered, and the absorbance was measured at $284 \mathrm{~nm}$.

To investigate the adsorption kinetics, $150 \mathrm{~mL}$ of CLOF solution (500 ppm, pH $3.00 \pm 0.20$ ) was mixed with $\sim 1.0 \mathrm{~g}$ of OSBC with shaking. An aliquot of $10 \mathrm{~mL}$ was withdrawn over a total time span of $60 \mathrm{~min}$. After each withdrawal, the solution was filtered, and the absorbance of the filtrate was measured at $284 \mathrm{~nm}$. The same procedure for investigating the adsorption kinetics was repeated using MAG-OSBC.

\subsection{Desorption and Regeneration Studies}

To explore the potential of adsorbent reusability, OSBC $(2.0 \mathrm{~g})$ was first equilibrated with $260 \mathrm{~mL}$ of $25 \mathrm{ppm}$ CLOF solution over a period of $2 \mathrm{~h}$ at room temperature. The mixture was then filtered. The adsorbent was washed with distilled water to remove any non-adsorbed traces of the CLOF and then dried in the oven at $70{ }^{\circ} \mathrm{C}$ for $48 \mathrm{~h}$. The previous procedures were repeated with MAG-OSBC using the same conditions. Eluents used in the current study were $0.1 \mathrm{M}$ of $\mathrm{HCl}, \mathrm{H}_{2} \mathrm{SO}_{4}, \mathrm{HNO}_{3}, \mathrm{Na}_{2} \mathrm{CO}_{3}$, ethanol as well as deionized water. The desorption experiment was performed by mixing $0.1 \mathrm{~g}$ of the CLOF-loaded adsorbent with $10 \mathrm{~mL}$ of the eluent. Samples were kept in the automatic shaker for $30 \mathrm{~min}$ at $150 \mathrm{rpm}$. The mixture was filtered, and the absorbance of the filtrate was measured at $284 \mathrm{~nm}$. Each of the desorption experiments was repeated three times, and the average values of the desorbed amount were plotted. Error bars were used to express the standard deviation between the replicate measurements.

Recovery studies were carried using ethanol. An amount of $0.2 \mathrm{~g}$ of OSBC was equilibrated with $25 \mathrm{~mL}$ of $20 \mathrm{ppm} \mathrm{CLOF}$ solution ( $\mathrm{pH} 3.0 \pm 0.2$ ) for $1 \mathrm{~h}$ at room temperature. The obtained mixture was then filtered, and the absorbance of the filtrate was measured at $284 \mathrm{~nm}$. The loaded adsorbent was eluted using ethanol, and $0.1 \mathrm{M} \mathrm{H}_{2} \mathrm{SO}_{4}$ for OSBC and MAG-OSBC, respectively, and samples were then left in the oven at $70^{\circ} \mathrm{C}$ for $1 \mathrm{~h}$, then used for another adsorption cycle. This process was renewed six times, and in each cycle, the removal efficiency $(\% R)$ was determined.

\subsection{Economics and Financial Assessment}

To assess the economic effects of the process of biochar production from agro-wastes, it is important to consider the cost of all materials as well as the energy consumption. Compared to the commercial adsorbents, agro-wastes (olive stones in our case) are of no cost. Moreover, upcycling waste material into a value-added product serves to relieve the burden on the environment that could be encountered if wastes were not properly recycled and reused. The estimated energy consumption per $\mathrm{kg}$ of activated carbon (OSBC) is $175.65 \mathrm{KWh} / \mathrm{kg}$ for an electricity tariff of 0.087 \$ KWh (Qatar, 2021). This included energy consumption by the oven and the furnace. The total price per $\mathrm{kg}$ is $15.28 \$$ compared to an average price of $124 \$ / 0.5 \mathrm{~kg}$ as per the Sigma-Aldrich website (shipping fees to Qatar are not included). Reagents used for the preparation of $12 \mathrm{~g}$ MAG-OSBC was: $\mathrm{NaOH}$, iron (III) 
and iron (II), with a cost of $0.024 \$, 0.88 \$$, and $0.43 \$$, respectively. The overall cost per $\mathrm{kg}$ of MAG-OSBC is $126.45 \$$ [29]. Though the cost of the magnetic biochar was higher compared to OSBC, it is important to consider the easiness of separation using an external magnet. Moreover, there is no reference cost for the commercial magnetic biochar, but just thinking about the price of the pristine commercial biochar as a starting material, we can see that the current approach is profitable.

\section{Results and Discussion}

\subsection{Adsorbent Characterization and Surface Chemistry}

3.1.1. Thermogravimetric Analysis (TGA)

The thermal stability of both adsorbents was studied using the TGA, Figure 1 . The obtained data show that both adsorbents are thermally stable in the range of $100-450{ }^{\circ} \mathrm{C}$. The weight loss between 50 and $100{ }^{\circ} \mathrm{C}$ was $7.09 \%$ and $13.61 \%$ for OSBC and MAG-OSBC, respectively, and could be attributed to the vaporization of free water. A considerable loss, $31.06 \%$ and $26.02 \%$, were observed between 550 and $800{ }^{\circ} \mathrm{C}$; for OSBC and MAG-OSBC, respectively, which could be due to the loss of organic matter and the carbonization of the polymeric material. The thermal stability of MAG-OSBC after $550{ }^{\circ} \mathrm{C}$ was higher compared to the OSBC due to the presence of magnetite on the surface.

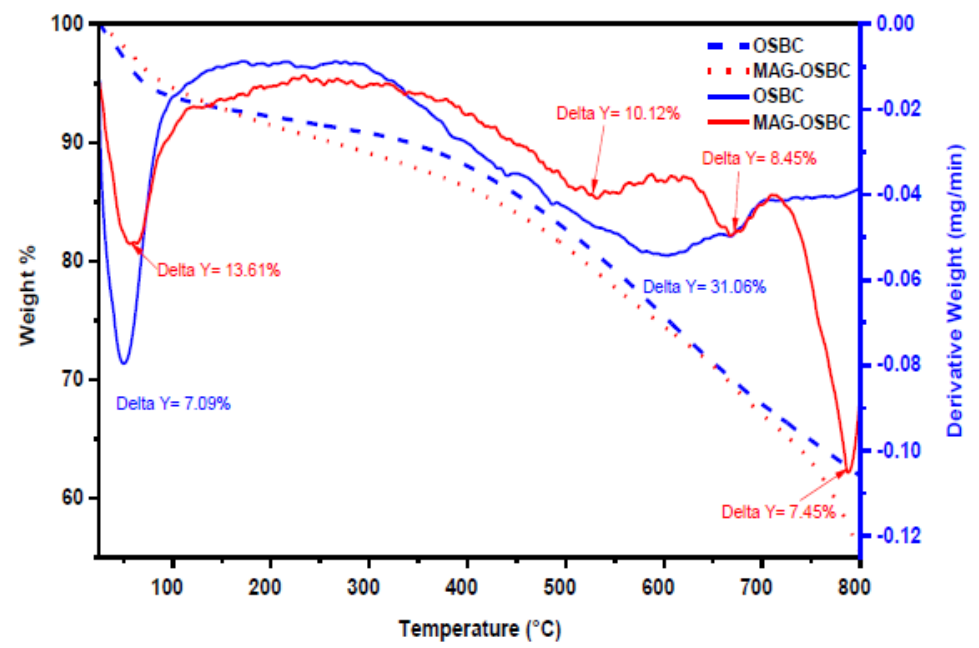

Figure 1. TGA/dTA analysis of olive stone biochars (OSBC) and magnetic olive stone biochar (MAG-OSBC).

\subsubsection{FT-IR Analysis and Point-of-Zero-Charge ( $\left.\mathrm{pH}_{\mathrm{PZC}}\right)$}

The functional groups on the surface of the prepared adsorbents before and following adsorption of CLOF, as well as for the free CLOF, were determined using FT-IR. Figure 2a shows the IR spectrum of both OSBC and MAG-OSBC before the adsorption. The obtained data show that both adsorbents possess almost similar spectra except for the sharp peak at $564 \mathrm{~cm}^{-1}$ in the spectrum of the MAG-OSBC. The presence of this peak is most likely because of the Fe-O bond vibration [41-43]. The band at $1580 \mathrm{~cm}^{-1}$ in the spectrum of OSBC could be assigned to the aromatic skeletal vibration in lignin. The two absorption bands at $1370 \mathrm{~cm}^{-1}$ and $1170 \mathrm{~cm}^{-1}$ are related to the $\mathrm{C}-\mathrm{H}$ deformation and $\mathrm{C}-\mathrm{O}-\mathrm{C}$ vibration, respectively. The absorption band at $890 \mathrm{~cm}^{-1}$ corresponds to the $\mathrm{C}-\mathrm{H}$ deformation in cellulose, and the band at $760 \mathrm{~cm}^{-1}$ is attributed to the aryl C-H or the aryl C-O groups [44]. 

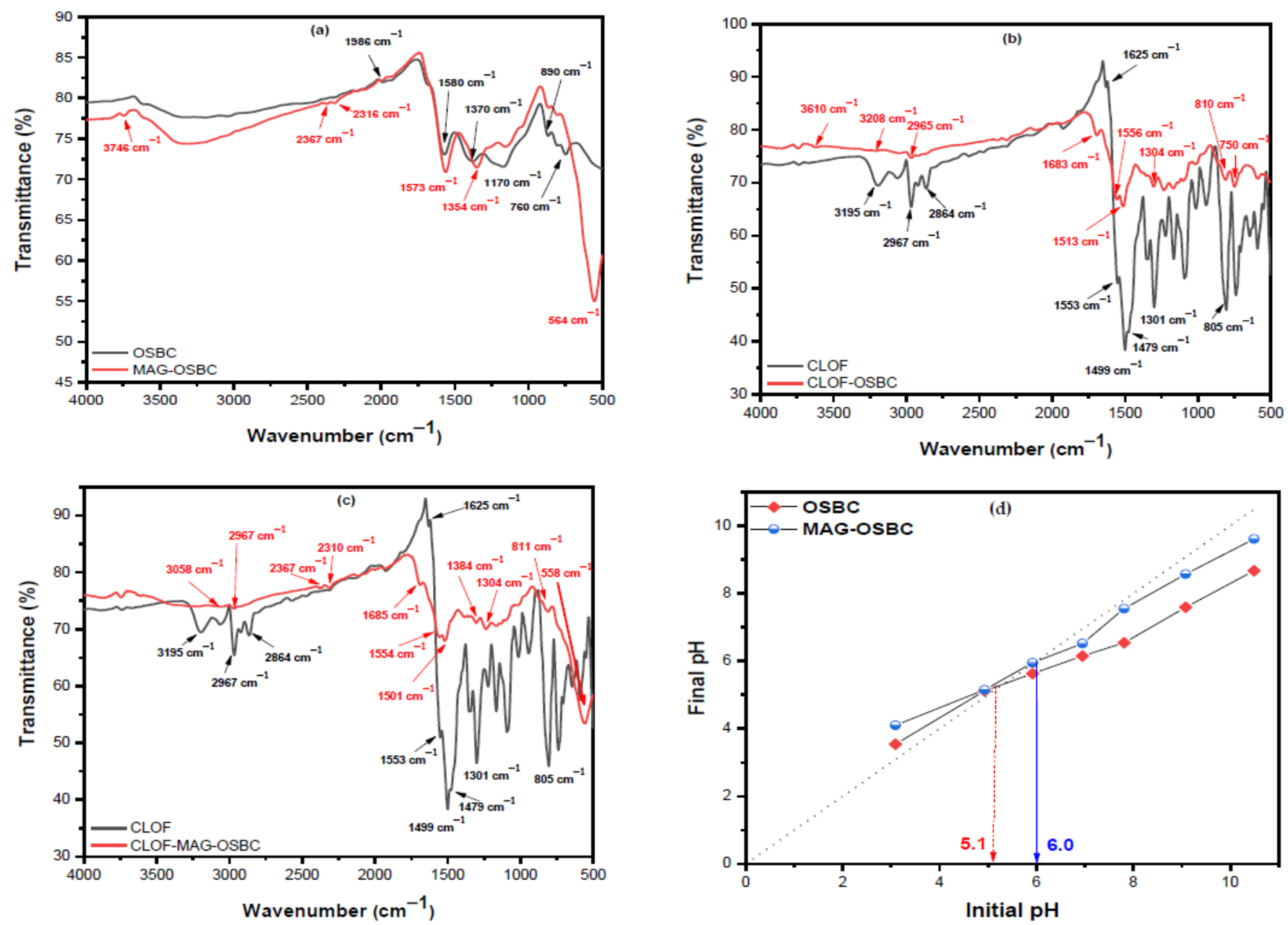

Figure 2. FT-IR spectra of OSBC and MAG-OSBC (a) before adsorption, (b) free CLOF and OSBC after adsorption, (c) free CLOF and MAG-OSBC after adsorption, $(\mathbf{d})$ point-of-zero-charge $\left(\mathrm{pH}_{\mathrm{PZC}}\right)$ for both adsorbents.

The spectrum of free CLOF is presented in Figure $2 \mathrm{~b}$. The spectrum shows strong characteristic absorption bands of the N-H bending frequency at $1550-1620 \mathrm{~cm}^{-1}$ and an absorption band at $1625 \mathrm{~cm}^{-1}$ corresponding to the $C=N$ stretching vibration $[45,46]$. Following the adsorption, the spectra of both OSBC and MAG-OSBC show the presence of the CLOF characteristic bands with a different intensity or shifted, implying the adsorption of CLOF onto OSBC and MAG-OSBC, Figure 2c.

Investigation of the $\mathrm{pH}_{\mathrm{PZC}}$ of both adsorbents showed that $\mathrm{OSBC}$ has a $\mathrm{pH}_{\mathrm{PZC}}$ of 5.1 compared to 6.0 in the case of MAG-OSBC, Figure 2d. These values are comparable to the previously reported values for OSBC [47,48]. Therefore, at a $\mathrm{pH}$ value of $3.0 \pm 0.2$ (lower bound), both adsorbents will have a positively charged surface compared to $\mathrm{pH}$ of $9.0 \pm 0.2$ (upper bound), where both will have a negatively charged surface. On the other hand, CLOF is of ampholytic nature with two $\mathrm{pK}_{\mathrm{a}}$ values, 2.31 and 9.29, Scheme 1 [10]. Therefore, CLOF will be in zwitterion form in the range of $2.31<\mathrm{pH}<9.29$, and the occurrence of electrostatic interaction between CLOF and either adsorbent within the investigated $\mathrm{pH}$ range may not be the best explanation for the adsorption mechanism.

\subsubsection{Raman Spectroscopy}

Raman spectra of the two adsorbents are shown in Figure 3. Two distinctive bands usually associated with carbonaceous materials could be observed: at $1359 \mathrm{~cm}^{-1}$ (D-band) and $1585 \mathrm{~cm}^{-1}$ (G-band). The D-band reflects the carbon lattice characteristics, such as the defects and the sizes, while the G-band reflects the $C-C$ stretching for the $s p^{2}$ system. 
The intensity ratio of the two bands, $\mathrm{I}_{\mathrm{D}}$ : $\mathrm{I}_{\mathrm{G}}$ in the case of OSBC, was 0.680 , compared to 0.565 in the case of MAG-OSBC. This finding reveals the presence of defects on the surface of the OSBC, and these defects have decreased following the loading with the magnetic nanoparticles, where the latter serves to cover some of these defects. On the other hand, the spectrum of MAG-OSBC reveals two weak broad peaks centered at 324 and $659 \mathrm{~cm}^{-1}$, which are associated with $\mathrm{Fe}-\mathrm{O}$ bond in magnetite [49-51]. The obtained data confirm the formation of the biochar and the presence of magnetite in the impregnated sample.

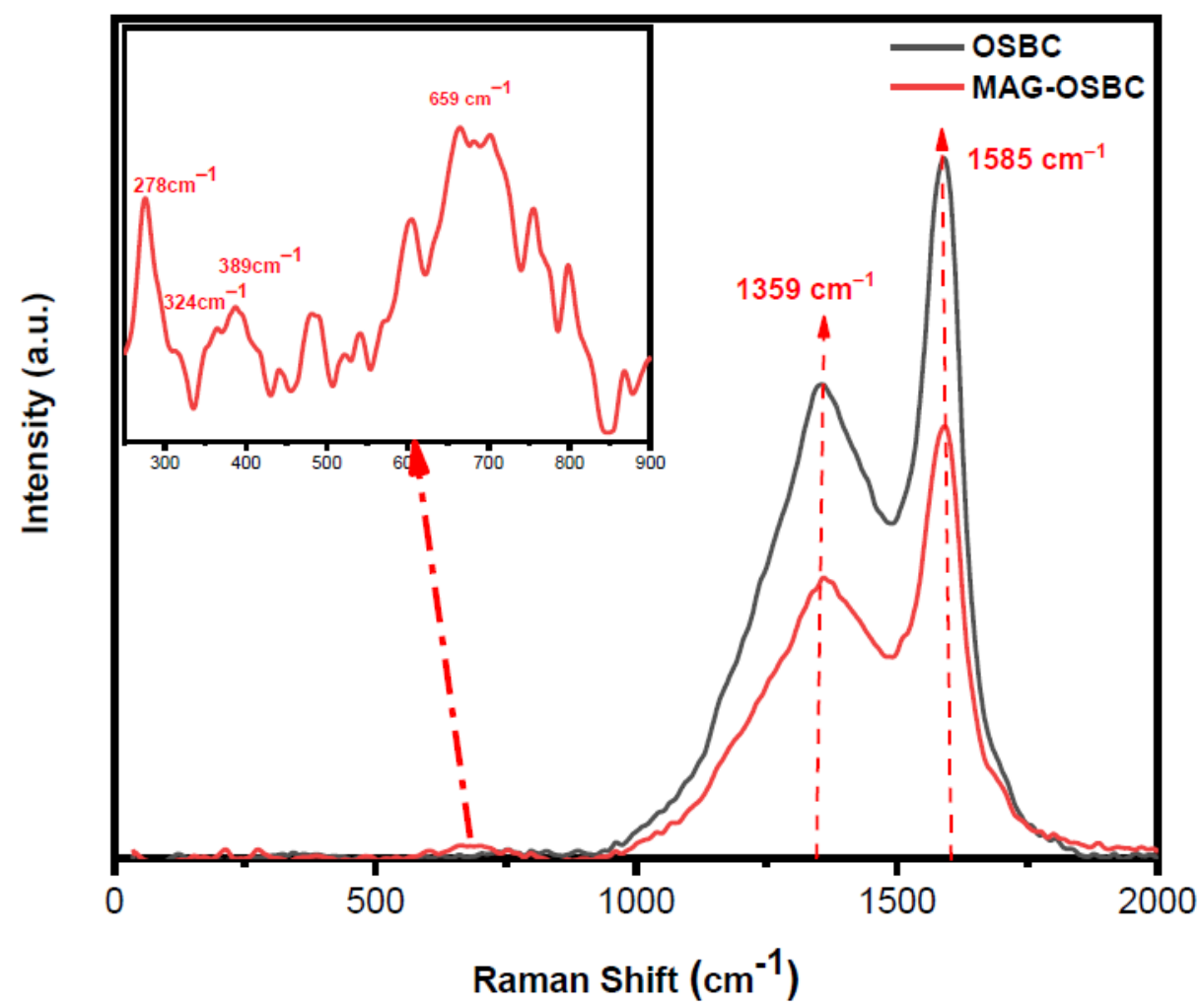

Figure 3. Raman spectra of OSBC and MAG-OSBC.

\subsubsection{Textural Properties}

Surface area, pore volume and pore radius as calculated by the Brunauer-EmmettTeller (BET) method are shown in Table 4 . The $\mathrm{N}_{2}$ adsorption-desorption isotherms are presented in Figure 4. Obtained data show that the Langmuir surface area has increased from $22.20 \mathrm{~m}^{2} / \mathrm{g}$ in the case of OSBC to $33.82 \mathrm{~m}^{2} / \mathrm{g}$ for MAG-OSBC. This behavior could be attributed to magnetic nanoparticles' presence on the surface of the OSBC, causing an increase in the surface area, which in turn could improve the removal efficiency towards CLOF. Furthermore, both adsorbents showed the presence of two types of pores: mesopores $(2-50 \mathrm{~nm})$ and macropores $(>50 \mathrm{~nm})$. The adsorption isotherm was of type IV for both adsorbents, implying monolayer-multilayer adsorption, followed by capillary condensation. The hysteresis loop for both adsorbents was of H3 type. This type is usually found on solids with an extensive pore size distribution, suggesting loose masses of plate-like particles forming slit-like pores [52].

Table 4. Brunauer-Emmett-Teller (BET) analyses of thermally treated olive stones before and after loading with magnetic nanoparticles, OSBC and MAG-OSBC, respectively.

\begin{tabular}{ccc}
\hline Parameters & OSBC & MAG-OSBC \\
\hline Langmuir surface area $\left(\mathrm{m}^{2} / \mathrm{g}\right)$ & 22.20 & 33.82 \\
Total pore volume $\left(\mathrm{cm}^{3} / \mathrm{g}\right)$ & 0.086 & 0.166 \\
Average pore radius $\left({ }^{\circ} \mathrm{A}\right)$ & 86.1 & 87.7 \\
\hline
\end{tabular}



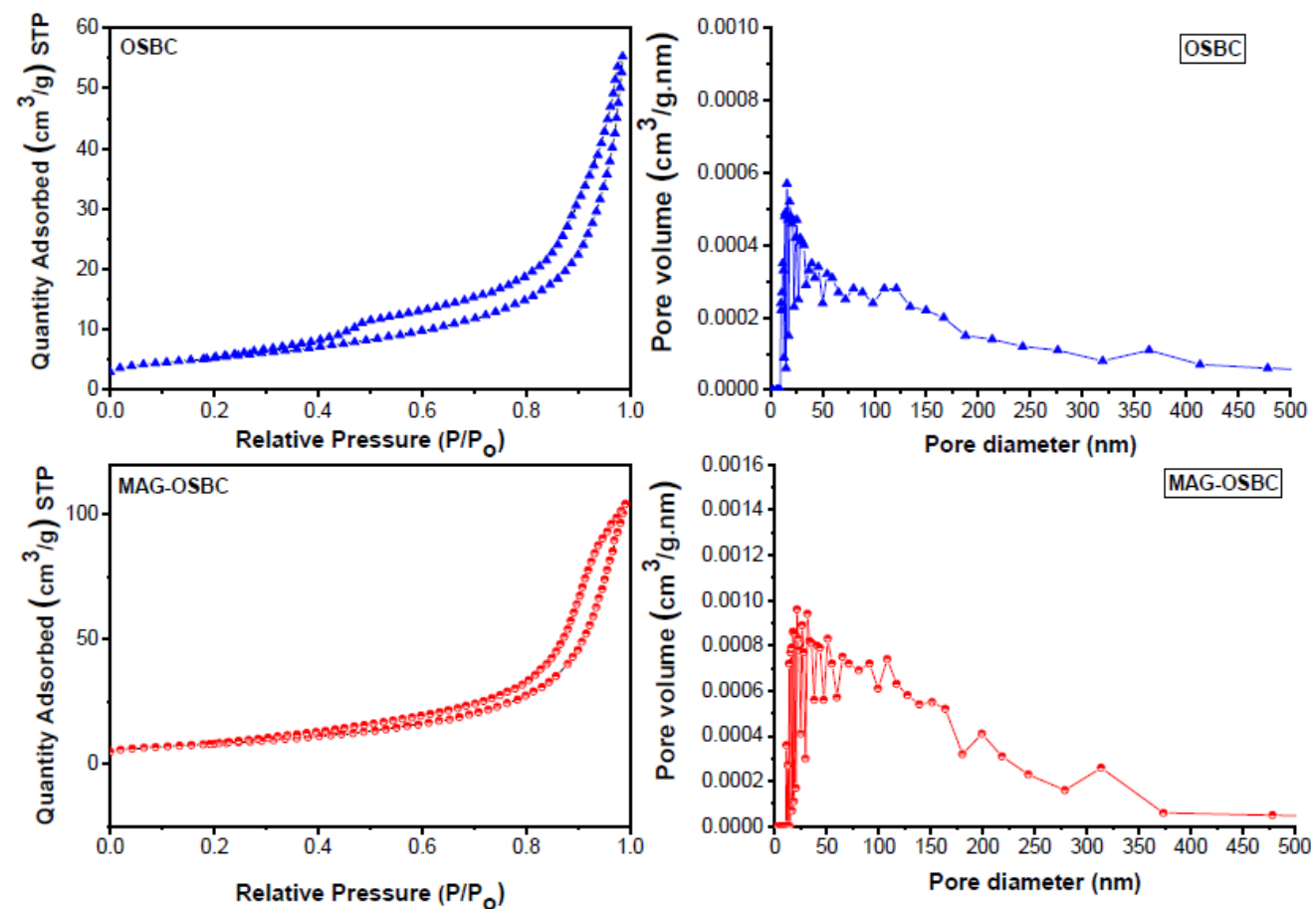

Figure 4. Nitrogen adsorption-desorption isotherms for the prepared adsorbents.

\subsubsection{Morphological Characteristics: SEM, EDX, and TEM Analyses}

The surface morphology, macroporosity and microscopic features of both adsorbents were visualized using SEM, SEM-EDX and TEM analyses. Figure $5 a, b$ displays the SEM micrographs for OSBC. Shown micrographs prove the presence of different types of pores (meso- and macropores) on the surface of the OSBC, as was confirmed by the BET analysis. For the MAG-OSBC (Figure 5c,d), magnetite nanoparticles appear on the surface, and the size of these particles will be confirmed using the TEM analysis. The SEM findings were further confirmed using the EDX analysis shown in Figure 5e,f. The EDX analysis of the OSBC revealed a high concentration of carbon $(88.15 \%)$ and oxygen $(11.85 \%)$, confirming the formation of carbonaceous material following the thermal treatment of the biomass. EDX data for the MAG-OSBC show iron with a concentration of $11.44 \%$ and oxygen with a concentration of $19.48 \%$, confirming the formation of iron oxide on the surface of the MAG-OSBC.

Microstructural characterization of the as-prepared nanoparticles on the surface of the MAG-OSBC was performed using the TEM analysis, Figure 6. The obtained TEM images agreed with the obtained SEM micrographs. Therefore-and while the surface of the OSBC appears as a clear surface (Figure $6 a, b$ ) - that of the MAG-OSBC (Figure 6c,d) looks rough where the magnetic nanoparticles could be easily observed on the surface. The average particle size of these nanoparticles was $11.75 \pm 1.64 \mathrm{~nm}$ (Figure 6e). The small particle size distribution (PSD) of $1.64 \mathrm{~nm}$ confirms the formation of uniform-sized magnetic nanoparticles on the surface of the carbonaceous material.

\subsubsection{X-ray Diffraction Analysis (XRD)}

X-ray diffraction analysis is an essential analytical technique that could be used to determine the crystalline phase of powdered materials. The samples were analyzed using powder X-ray diffraction analysis to verify the crystalline phase of the as-prepared magnetite nanoparticles. The data shown in Figure 7 represents the XRD diffractogram pattern of both OSBC and MAG-OSBC. The obtained XRD pattern for the OSBC sample shows a broad peak in the range of $2 \theta 17^{\circ}-28^{\circ}$, signifying the amorphous state of the OSBC. The same was observed for the MAG-OSBC, confirming the presence of a carbon layer with magnetite nanoparticles [53]. On the other hand, the XRD pattern of the MAG-OSBC 
shows three intense peaks that could be assigned to cubic $\mathrm{Fe}_{3} \mathrm{O}_{4}$ (ICDD: 98-015-8743) at $2 \theta 30.15^{\circ}, 35.59^{\circ}$, and $57.27^{\circ}$. These findings are in good agreement with the similar observation that was previously reported $[53,54]$. The obtained findings confirm the presence of cubic $\mathrm{Fe}_{3} \mathrm{O}_{4}$ magnetic nanoparticles on the surface of the MAG-OSBC. The XRD analysis can also be used to determine the particle size using the Scherrer Equation (4) [55]. The prepared sample's crystal size can be calculated from line broadening of the tested sample XRD pattern.

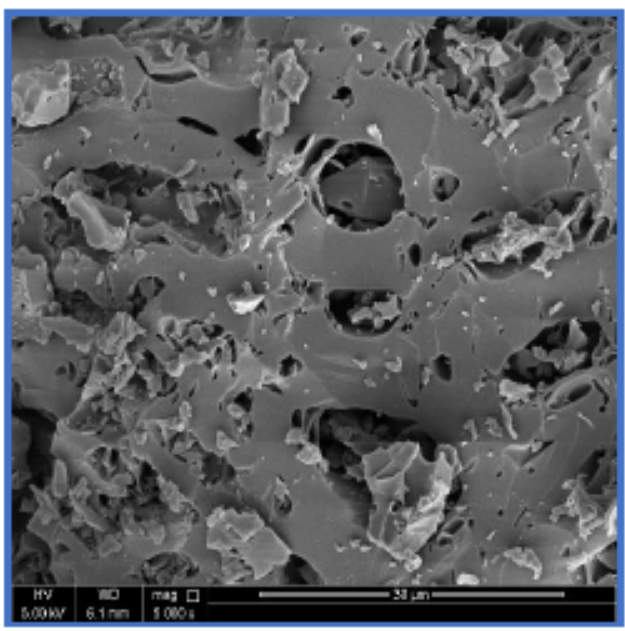

(a)

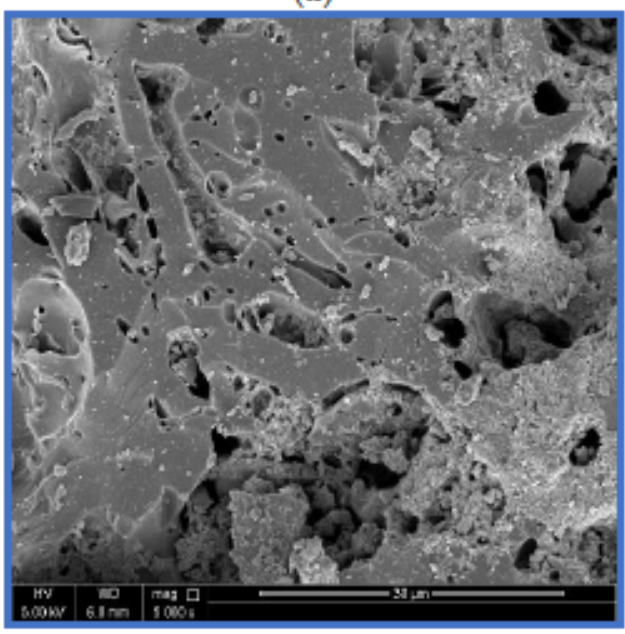

(c)

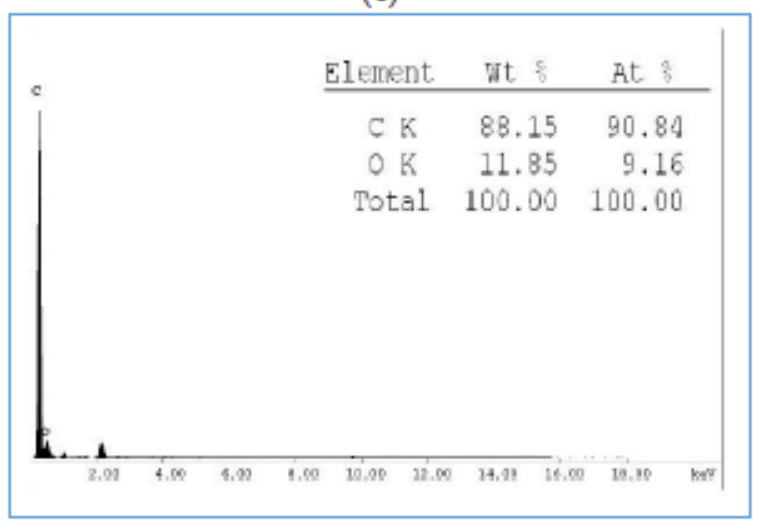

(e)

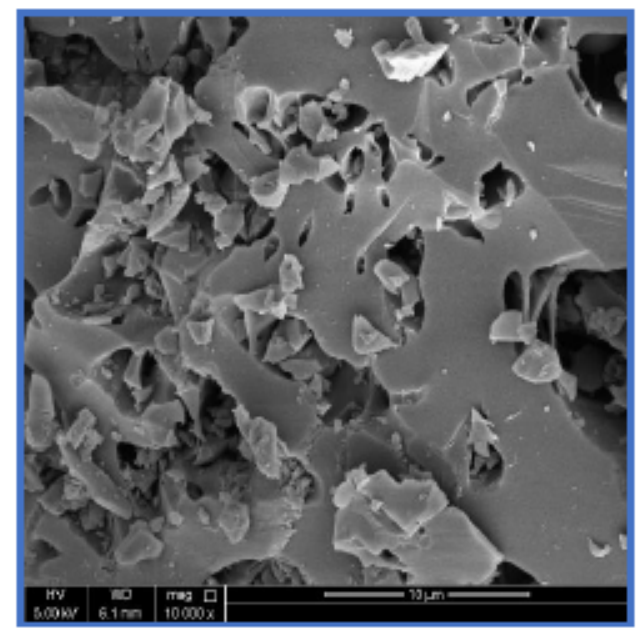

(b)

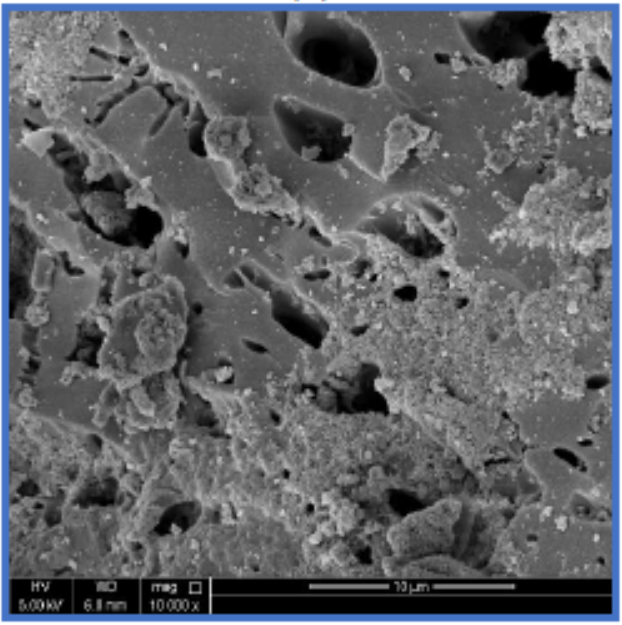

(d)

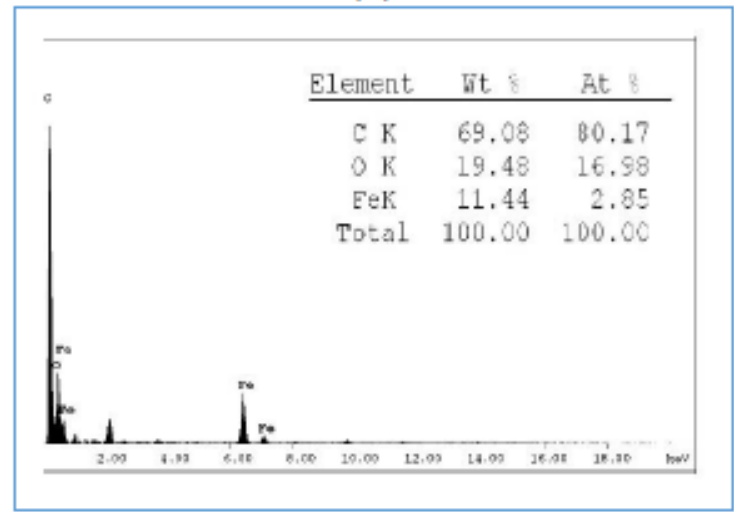

(f)

Figure 5. SEM micrographs of (a,b) OSBC, (c,d) MAG-OSBC at 5000 $\times$ and 10,000 $\times$ magnifications, (e,f) EDX analyses of OSBC and MAG-OSBC, respectively. 


$$
D=\frac{K \lambda}{B \cos \theta}
$$

where $\lambda$ is the $X$-ray wavelength that equals $0.15406 \mathrm{~nm}, B$ is the corrected width of the major XRD peak of the studied sample at the half-height and at each corresponding angle $\theta$, and $K$ is a shape factor in this case, equals 0.89 . The average particle size $D(\mathrm{~nm})$ of the prepared magnetite was estimated from XRD line broadening using the Scherrer equation, and it was found to be $22.66 \mathrm{~nm}$, which is close to the obtained data from PSD of the TEM analysis.

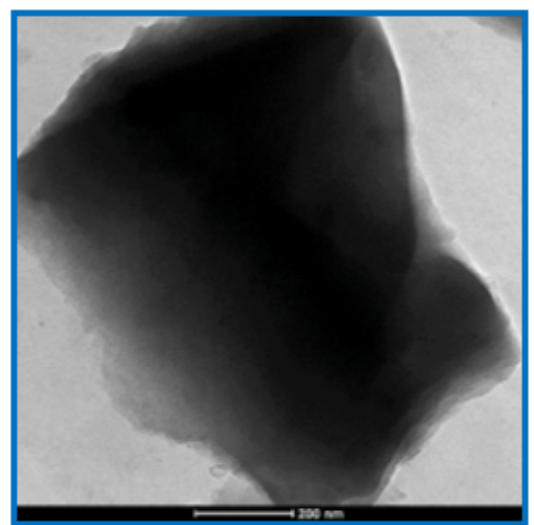

(a)

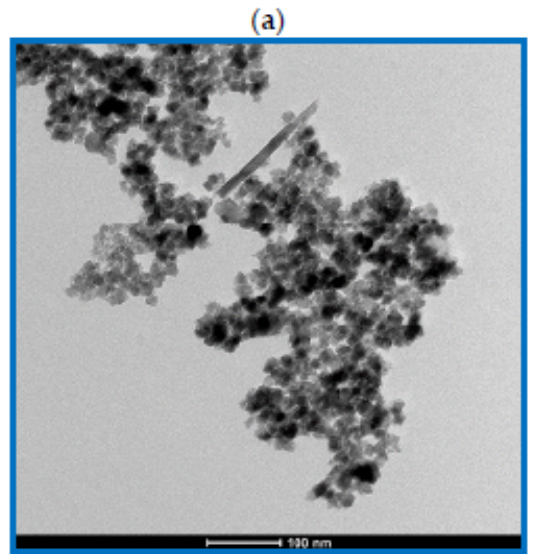

(c)

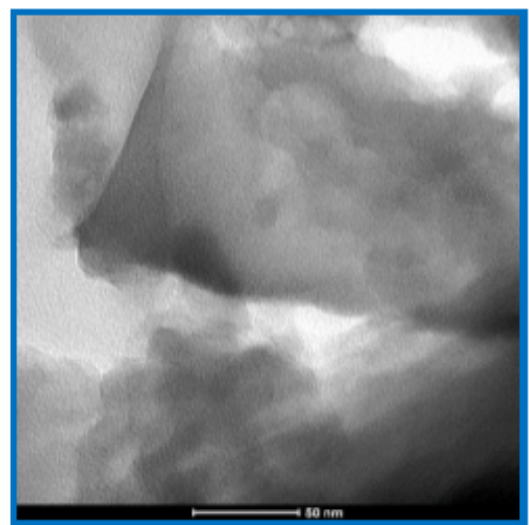

(b)

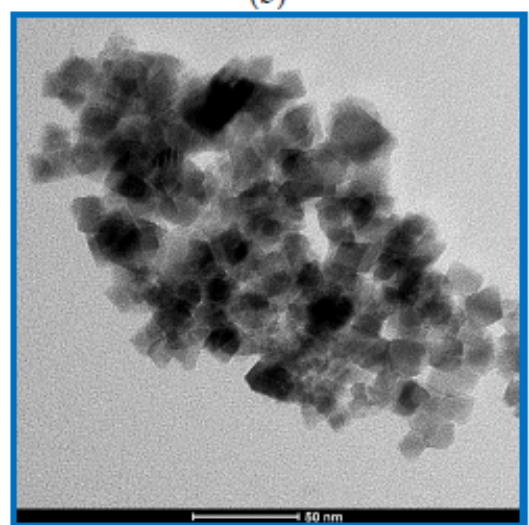

(d)

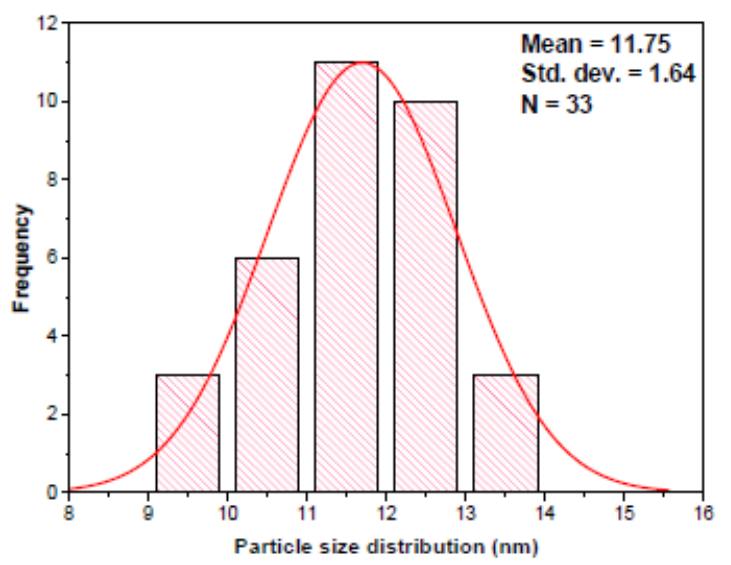

(e)

Figure 6. TEM images of the OSBC at two scales (a) $200 \mathrm{~nm}$, (b) $50 \mathrm{~nm}$ and MAG-OSBC at (c) $100 \mathrm{~nm}$, (d) $50 \mathrm{~nm}$ and (e) PSD results for the MAG-OSBC. 


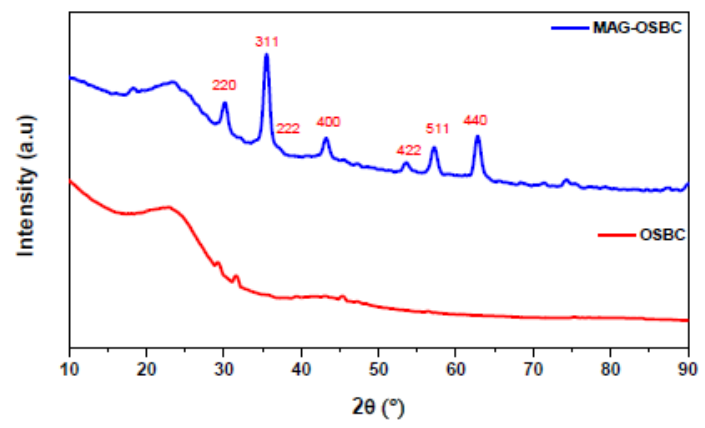

Figure 7. Powder XRD pattern of the OSBC and MAG-OSBC.

\subsection{Box-Behnken (BB) Design}

Batch adsorption experiments were conducted following the BB design matrix shown in Table 2. BB design is a second-order response surface design, which is operated at three levels for each variable. This design is utilized if the number of the predictors is between 3 and 12. One of the advantages of the BB design is that variables are not studied at their extreme levels, meaning that the design does not have runs that measure all variables at the highest points and the lowest points simultaneously $[14,29,38,39,56]$. Compared to the other RSM designs, e.g., the central composite designs (CCD), BB design entails fewer runs [57].

\subsubsection{Investigation of the Statistically Significant Variables}

To investigate the significance of the studied factors, the Pareto chart of standardized effects was constructed, Figure 8 . When $\% \mathrm{R}$ is the maximized response, the CT (C-linear in case of OSBC and squared in case of MAG-OSBC) was the most statistically significant factor. The magnitude of the impact of $\mathrm{pH}(\mathrm{D})$ was much less significant on both adsorbents. With $q_{e}$, however, the impact of [CLOF] (B) was the most significant for both adsorbents followed by the AD (A)-Figures are not shown. These findings further confirm the results of FT-IR analysis and the obtained $\mathrm{pH}_{\mathrm{PZC}}$, where $\mathrm{pH}$ has almost no effect on the measured responses, an issue that supports the probability of occurrence of physisorption compared to chemisorption.
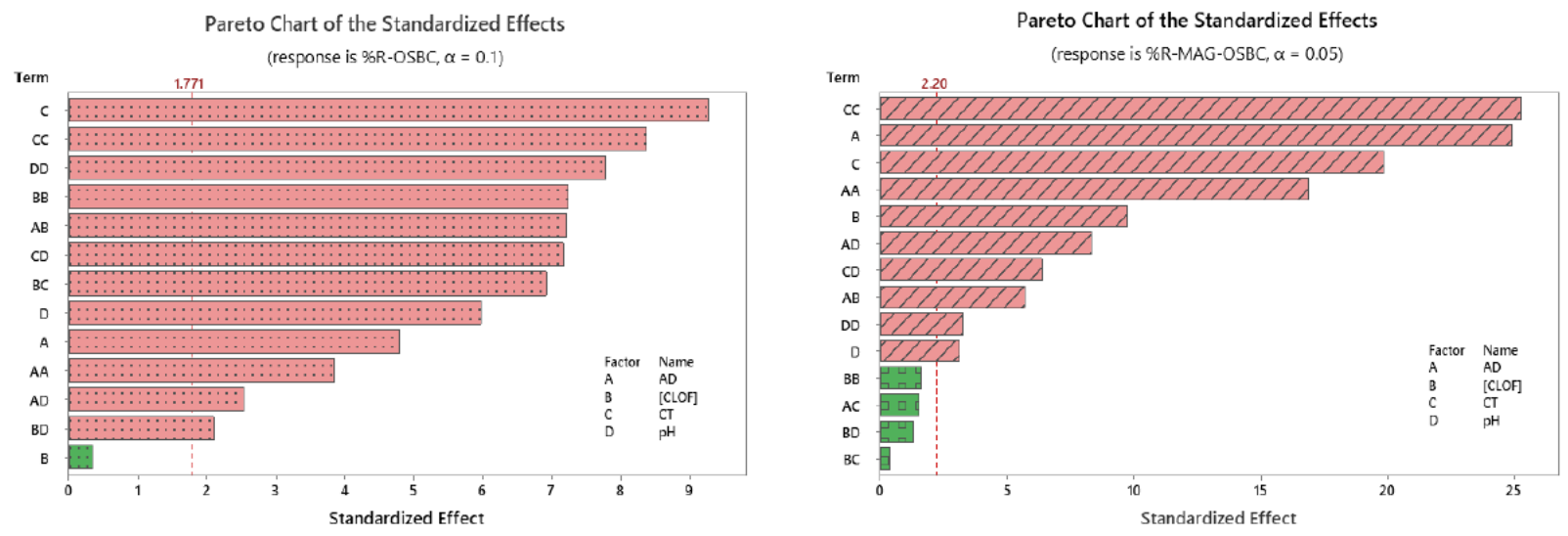

Figure 8. Pareto chart of standardized effects when $\% R$ is the optimized response.

\subsubsection{Analysis of Variance (ANOVA)}

Following the fitting of Equation (3) to the data shown in Table 3, the following polynomial regression models were obtained, Equations (5)-(8). These equations give a clear and comprehensive description of the relationship between dependent and independent variables. Therefore, the overall effect of any variable on the measured response could be simply computed using these equations. The summary of these models is shown in Table 5. 
The revealed values of the coefficient of determination $\left(R^{2}\right)$ and $R^{2}$-adjusted $\left(R^{2}\right.$-adj) are high enough, reflecting the linearity of obtained models. The models' ability to foretell the response for a new observation is expressed by the value of the $R^{2}$-predicted $\left(R^{2}\right.$-pred). The high values of the $\mathrm{R}^{2}$-pred reflect a reasonable capability of the obtained regression models. The experimental values' agreement with the predicted ones was expressed by the small values of the relative error (RE), Table 3.

Table 5. Summary of the regression models, Equations (5)-(8).

\begin{tabular}{|c|c|c|c|c|}
\hline Optimized Response & $R^{2 \%}$ & $\mathbf{R}^{2}-\mathbf{A d j} \%$ & $\mathbf{R}^{2}-$ Pred $\%$ & Optimum conditions \\
\hline$\% \mathrm{R}_{(O S B C)}$ & 97.76 & 95.53 & 90.42 & $\begin{array}{c}\mathrm{AD}=100 \mathrm{mg},[\mathrm{CLOF}]=25 \mathrm{ppm}, \mathrm{CT}=35 \mathrm{~min}, \mathrm{pH}=3.0 \\
(d=1.0000, \% \mathrm{R}=100 \%)\end{array}$ \\
\hline$q_{e}(O S B C)$ & 98.81 & 97.42 & 93.32 & $\begin{array}{c}\mathrm{AD}=30 \mathrm{mg},[\mathrm{CLOF}]=60 \mathrm{ppm}, \mathrm{CT}=85 \mathrm{~min}, \mathrm{pH}=3.0 \\
\left(d=1.0000, q_{e}=18.42 \mathrm{mg} / \mathrm{g}\right)\end{array}$ \\
\hline$\% \mathrm{R}_{(M A G-O S B C)}$ & 99.52 & 98.86 & 96.65 & $\begin{array}{c}\mathrm{AD}=110 \mathrm{mg},[\mathrm{CLOF}]=10 \mathrm{ppm}, \mathrm{CT}=65 \mathrm{~min}, \mathrm{pH}=3.0 \\
(d=1.0000, \% \mathrm{R}=100 \%)\end{array}$ \\
\hline$q_{e}(M A G-O S B C)$ & 99.86 & 99.66 & 99.05 & $\begin{array}{c}\mathrm{AD}=30 \mathrm{mg},[\mathrm{CLOF}]=60 \mathrm{ppm}, \mathrm{CT}=63 \mathrm{~min}, \mathrm{pH}=6.0 \\
\left(d=1.0000, q_{e}=14.62 \mathrm{mg} / \mathrm{g}\right)\end{array}$ \\
\hline
\end{tabular}

The results for ANOVA testing-Tables are not shown, were in a good match with the findings of the Pareto chart as well as the regression models, where variables with a probability value ( $p$-value) of $<0.05$ (confidence level 95.0 ) are statistically significant.

$$
\begin{gathered}
\% \mathrm{R}_{(O S B C)}=96.3+1.079 \mathrm{AD}+2.565[\mathrm{CLOF}]-0.034 \mathrm{CT}-34.87 \mathrm{pH}-0.00423 \mathrm{AD} \times \mathrm{AD}-0.02581 \\
{[\mathrm{CLOF}] \times[\mathrm{CLOF}]-0.01168 \mathrm{CT} \times \mathrm{CT}+1.926 \mathrm{pH} \times \mathrm{pH}-0.01649 \mathrm{AD} \times[\mathrm{CLOF}]} \\
+0.0484 \mathrm{AD} \times \mathrm{pH}+0.01781[\mathrm{CLOF}] \times \mathrm{CT}-0.0722[\mathrm{CLOF}] \times \mathrm{pH}+0.1538 \mathrm{CT} \times \mathrm{pH} \\
q_{e(O S B C)}=4.44-0.0515 \mathrm{AD}+0.4048[\mathrm{CLOF}]+0.0525 \mathrm{CT}-1.804 \mathrm{pH}+0.000393 \mathrm{AD} \times \mathrm{AD}-0.000883 \\
{[\mathrm{CLOF}] \times[\mathrm{CLOF}]-0.000636 \mathrm{CT} \times \mathrm{CT}+0.0794 \mathrm{pH} \times \mathrm{pH}-0.002491 \mathrm{AD} \times[\mathrm{CLOF}]-0.000592 \mathrm{AD}} \\
\times \mathrm{CT}+0.00725 \mathrm{AD} \times \mathrm{pH}+0.000819[\mathrm{CLOF}] \times \mathrm{CT}-0.01020[\mathrm{CLOF}] \times \mathrm{pH}+0.00743 \mathrm{CT} \times \mathrm{pH} \\
\sqrt{ } \% \mathrm{R}_{(M A G-O S B C)}=-2.513+0.14058 \mathrm{AD}+0.0258[\mathrm{CLOF}]+0.13486 \mathrm{CT}+0.7086 \mathrm{pH}-0.000546 \mathrm{AD} \\
\times \mathrm{AD}-0.000158[\mathrm{CLOF}] \times[\mathrm{CLOF}]-0.000909 \mathrm{CT} \times \mathrm{CT}-0.02002 \mathrm{pH} \times \mathrm{pH}-0.000337 \mathrm{AD} \\
\times[\mathrm{CLOF}]-0.000056 \mathrm{AD} \times \mathrm{CT}-0.003941 \mathrm{AD} \times \mathrm{pH}+0.000023[\mathrm{CLOF}] \times \mathrm{CT}-0.001130 \\
{[\mathrm{CLOF}] \times \mathrm{pH}-0.003535 \mathrm{CT} \times \mathrm{pH}} \\
\ln \left(q_{\text {e(MAG-OSBC })}=-1.407+0.00157 \mathrm{AD}+0.08076[\mathrm{CLOF}]+0.03451 \mathrm{CT}+0.1622 \mathrm{pH}-0.000024 \mathrm{AD}\right. \\
\times \mathrm{AD}-0.000580[\mathrm{CLOF}] \times[\mathrm{CLOF}]-0.000228 \mathrm{CT} \times \mathrm{CT}-0.00463 \mathrm{pH} \times \mathrm{pH}-0.000069 \mathrm{AD} \\
\times[\mathrm{CLOF}]-0.000023 \mathrm{AD} \times \mathrm{CT}-0.000709 \mathrm{AD} \times \mathrm{pH}+0.000008[\mathrm{CLOF}] \times \mathrm{CT}-0.000472[\mathrm{CLOF}] \\
\times \mathrm{pH}-0.000893 \mathrm{CT} \times \mathrm{pH}
\end{gathered}
$$

\subsubsection{Response Optimization}

Contour (2D) and surface (3D) plots were used to ascertain the impact of a certain set of variables on the measured response(s). Sample contour plot when $\% \mathrm{R}$ is the response being measured and OSBC is the adsorbent shown in Figure 9. The legend on the right of the plots shows the range of $\% R$ and the corresponding color. Figure 9-upper left graph shows the impact of the combination of two variables, [CLOF] and the $\mathrm{AD}$, represented on the $y$-and $x$-axis, respectively. As shown, a $\% \mathrm{R}$ of $80-100 \%$ could be achieved using an AD of $60-120 \mathrm{mg}$ and [CLOF] of $0-40 \mathrm{ppm}$. 


\section{Contour Plots of \%R-OSBC}
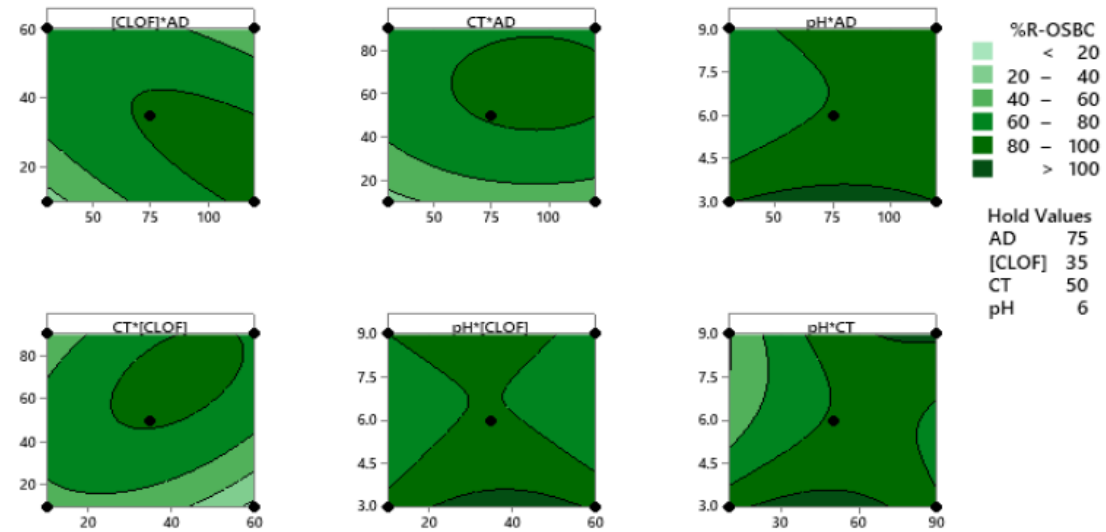

Figure 9. Sample contour plots when $\% \mathrm{R}$ is the response, using OSBC as an adsorbent.

Optimization of the individual responses was performed using the response optimizer tool provided by Minitab ${ }^{\circledR}$. Optimum conditions (factorial combinations) that could maximize a response are shown in Table 5. The favorability of any factorial combination was assessed by the value of the desirability function $(d)$, where the closer the value of $d$ to 1.000 , the better the combination. Obtained $d$ values are also reported in Table 5 together with the maximum responses obtained using these factorial combinations [58].

\subsection{Adsorption Isotherms and Kinetic Studies}

By and large, the adsorption capability of an adsorbent is dependent on the functionalities existing on the surface of the adsorbent as well as its surface area. Based on the obtained characterization data and the BB design output, different types of interactions could be proposed for the interaction of CLOF and either adsorbent.

\subsubsection{Adsorption Isotherms}

Adsorption isotherms can be used to determine the degree of accumulation of the adsorbate on the adsorbent's surface and the type of interaction between the adsorbate and the adsorbent. Four equilibrium isotherms, including Langmuir, Freundlich, Temkin, and Dubinin-Radushkevich (D-R), have been used to investigate the adsorption of CLOF on both adsorbents at a constant temperature [59-62].

Langmuir isotherm usually indicates three hypotheses: (I) all adsorption sites on the adsorbent have constant adsorption energy, (II) each adsorbate molecule occupies only one site on the adsorbent and no interaction between the adsorbate molecules, lastly (III) the adsorption is localized. It can be presented by Equation (9) and Figure 10a for the OSBC and Figure 10b for the MAG-OSBC.

$$
q_{e}=\frac{q_{m} K_{L} C_{e}}{1+K_{L} C_{e}}
$$

where $q_{m}$ is the maximum adsorption capacity and $K_{L}$ is the Langmuir equilibrium coefficient. In addition, the Langmuir model can be presented using the following dimensionless format, Equation (10):

$$
R_{L}=\frac{1}{1+K_{L} C_{0}}
$$

where $R_{L}$ and $C_{0}(\mathrm{ppm})$ are the separation factor and initial concentration of CLOF, respectively. Based on the literature, the $R_{L}$ value can determine the adsorption favorability; thus, if $R_{L}$ is $>1$, then the adsorption process is considered as unfavorable, while if the $R_{L}=1$, then the adsorption is linear and if the value is between 0 and 1 , the adsorption is favorable and can occur spontaneously. However, if the $R_{L}$ value is zero, then the ad- 
sorption is irreversible. The obtained $R_{L}$ value for OSBC and MAG-OSBC was found to be $<1$, indicating that the adsorption process was spontaneous on both adsorbents and at higher concentrations of CLOF, the process became irreversible with maximum adsorption capacity $\left(q_{\max }\right)=137.90$ and $174.03 \mathrm{mg} / \mathrm{g}$ for OSBC and MAG-OSBC, respectively. This finding shows that the MAG-OSBC as an adsorbent possesses a higher adsorptive capability for CLOF, and this behavior could be related to the higher surface area and pore volume compared to the pristine OSBC. Studies using zinc chloride-activated carbon prepared from olive stone (ACOS), magnetic adsorbent from the olive kernel (MA-OK), and olive stones chemically activated with phosphoric acid showed that Langmuir isotherm could best describe the adsorption of the investigated organic pollutants $[33,35,36]$.
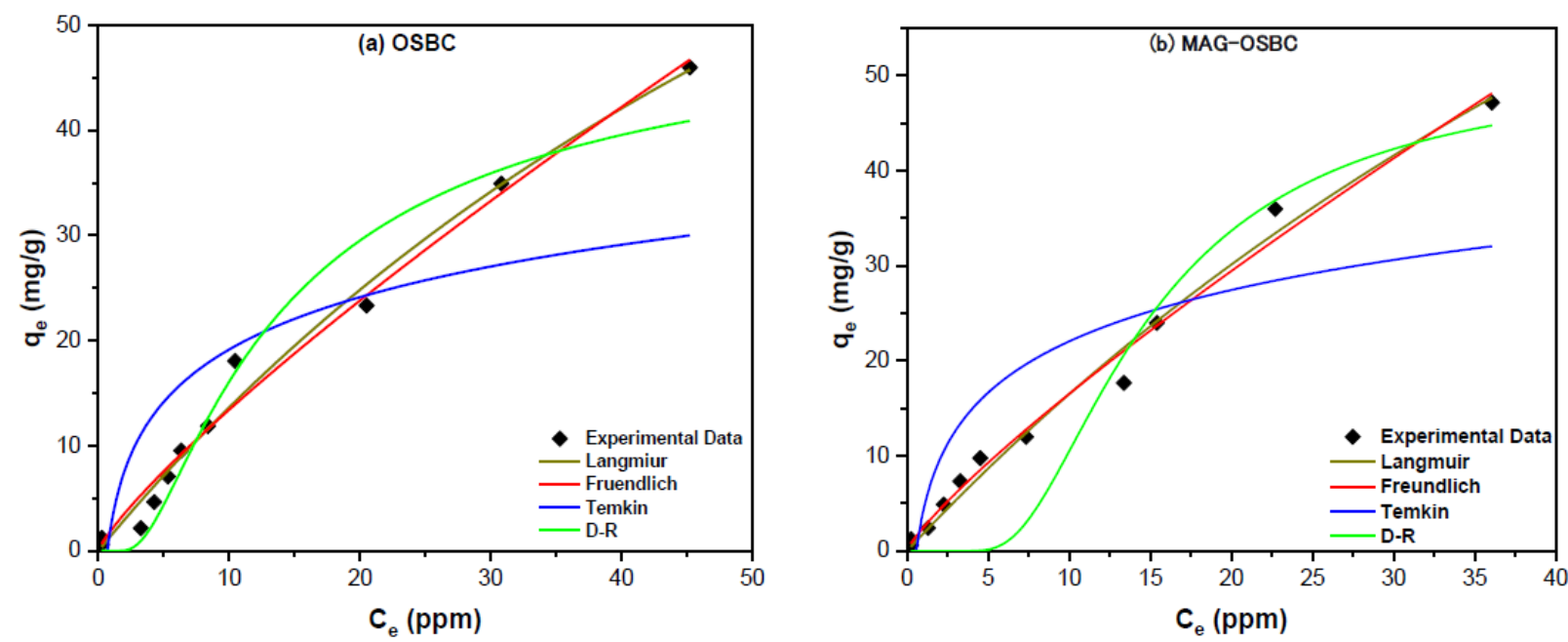

Figure 10. Adsorption isotherms of CLOF onto (a) OSBC and (b) MAG-OSBC, including Langmuir, Freundlich, Temkin, and Dubinin-Radushkevich (D-R) isotherms.

The obtained data show that the performance of the current adsorbents is comparable to the conventional adsorbents. For example, the reported $q_{\max }$ of a commercial activated carbon (Filtrasorb 400) towards diclofenac was $180 \mathrm{mg} / \mathrm{g}$ [63]. The performance was even better when compared to the multi- and single-walled carbon nanotubes towards hydrochlorothiazide with $q_{\max }$ of $66.22 \mathrm{mg} / \mathrm{g}$ and $45.66 \mathrm{mg} / \mathrm{g}$, respectively [64].

The Freundlich isotherm is a purely empirical approach that can be used to describe the energy of the heterogeneous surface, and it is given by Equation (11):

$$
q_{e}=K_{F} C_{e}^{\frac{1}{n}}
$$

where $C_{e}$ is the equilibrium concentration of CLOF (ppm); $q_{e}$ is the amount of CLOF adsorbed/unit mass $\left(\mathrm{mg} \cdot \mathrm{g}^{-1}\right), K_{F}\left(\right.$ mole $\left.\cdot \mathrm{g}^{-1}\right)\left(\mathrm{L} \cdot \mathrm{mole}^{-1}\right)$ and $1 / n$ are the Freundlich coefficients that express the adsorbent capacity and change in the intensity of the adsorption, as well as the deviation from linearity, Figure 10a,b for the OSBC and MAG-OSBC, respectively and their values, are listed in Table 6 . The obtained data from the Freundlich isotherm showed a good fit with an $\mathrm{R}^{2}=0.984$ and 0.988 for both OSBC and MAG-OSBC, respectively, which is similar to the $R^{2}$ values obtained for the Langmuir isotherm $\left(R^{2}=0.986\right.$ for OSBC and 0.988 for MAG-OSBC), implying that both Langmuir and Freundlich isotherms can be used to describe the adsorption of CLOF onto both adsorbents. Table 6 shows that the values of the $1 / n=0.82, n=1.22$ for OSBC and $1 / n=0.83, n=1.20$ for the MAG-OSBC. Accordingly, the adsorption potential $(\mathrm{A}=\mathrm{nRT})=4.02 \mathrm{~kJ}$, and any CLOF molecule with a potential energy $<4.02 \mathrm{~kJ}$ can be adsorbed onto the surface of MAG-OSBC, and the adsorption tend to be favorable and irreversible. A study using acid-treated olive stones (ATOS) showed that Freundlich isotherm could be best describe the adsorption of the pesticides onto the surface of the ATOS [31]. 
Table 6. Nonlinear equations of Langmuir, Freundlich, Temkin and Dubinin-Radushkevich (D-R) isotherms, besides their parameters for the adsorption of CLOF onto both OSBC and MAG-OSBC.

\begin{tabular}{|c|c|c|c|c|}
\hline \multirow{2}{*}{ Isotherm } & \multirow{2}{*}{$\begin{array}{l}\text { Equations (Nonlinear } \\
\text { Forms) }\end{array}$} & \multirow{2}{*}{ Parameters } & \multicolumn{2}{|c|}{ Value } \\
\hline & & & OSBC & MAG-OSBC \\
\hline \multirow{3}{*}{ Langmuir } & \multirow{3}{*}{$q_{e}=\frac{q_{m} K_{L} C_{e}}{1+K_{L} C_{e}}$} & $q_{m}(\mathrm{mg} / \mathrm{g})$ & 137.90 & 174.03 \\
\hline & & $K_{L}\left(\mathrm{~L} \cdot \mathrm{mole}^{-1}\right)$ & 0.011 & 0.010 \\
\hline & & $\mathrm{R}^{2}$ & 0.9865 & 0.9879 \\
\hline \multirow{3}{*}{ Freundlich } & \multirow{3}{*}{$q_{e}=K_{F} C_{e}^{\frac{1}{n}}$} & $1 / \mathrm{n}$ & 0.82 & 0.83 \\
\hline & & $K_{F}($ mole $/ \mathrm{g})(\mathrm{L} / \text { mole })^{1 / \mathrm{n}}$ & 2.00 & 2.42 \\
\hline & & $\mathrm{R}^{2}$ & 0.9842 & 0.9886 \\
\hline \multirow{3}{*}{ Temkin } & \multirow{3}{*}{$q_{e}=\frac{R T}{b_{T}} \ln \left(A_{T} C_{e}\right)$} & $b_{T}(\mathrm{~J} / \mathrm{mole})$ & 344.6 & 317.4 \\
\hline & & $A_{T}(\mathrm{~L} /$ mole $)$ & 1.435 & 1.685 \\
\hline & & $\mathrm{R}^{2}$ & 0.6334 & 0.7346 \\
\hline \multirow{4}{*}{ D-R } & \multirow{4}{*}{$\begin{array}{c}q_{e}=q_{s} \cdot \exp \left(-\beta \cdot \varepsilon^{2}\right) \\
\epsilon=R T\left(1+\frac{1}{C_{e}}\right) \\
E=1 / \sqrt{2 \beta}\end{array}$} & $\beta$ & $2.74 \times 10^{-8}$ & $5.67 \times 10^{-8}$ \\
\hline & & $E(\mathrm{~kJ} / \mathrm{mole})$ & 4.271 & 2.969 \\
\hline & & $q_{m}(\mathrm{mg} / \mathrm{g})$ & 149.32 & 50.99 \\
\hline & & $\mathrm{R}^{2}$ & 0.9603 & 0.8792 \\
\hline
\end{tabular}

$q_{e}$ : amount of adsorbate in the adsorbent at equilibrium, $K_{L}$ : Langmuir isotherm constant, $q_{m}$ : maximum monolayer coverage capacities, $K_{F}$ : Freundlich adsorption constant, $C_{e}$ : equilibrium concentration, $q_{s}$ : theoretical isotherm saturation capacity, $A_{T}$ : Temkin isotherm equilibrium binding constant, $R$ : universal gas constant $(8.314 \mathrm{~J} / \mathrm{mol} \mathrm{K}), T$ is the temperature $(\mathrm{K}), b_{T}$ : Temkin isotherm constant, $\beta$ : is a constant related to the adsorption energy and $\epsilon$ : is the adsorption potential.

Temkin isotherm, Figure 10, could provide an idea about the interaction between the adsorbate and the adsorbent, where the heat of the adsorption of adsorbed molecules in a layer decreases linearly with the adsorbent-adsorbate interactions. According to the data presented in Table 6, the sorption energy is $344.6 \mathrm{~J} / \mathrm{mol}$ for the OSBC and $317.4 \mathrm{~J} / \mathrm{mol}$ for the MAG-OSBC. These findings imply the favorable adsorption of CLOF onto both adsorbents and confirm the obtained data from Langmuir and Freundlich isotherms.

Finally, the D-R equilibrium isotherm was studied at room temperature, Figure 10, and Table 6. The obtained data for both adsorbents show that the sorption energy for OSBC is $4.271 \mathrm{~kJ} / \mathrm{mol}$ and $2.969 \mathrm{~kJ} / \mathrm{mol}$ for the MAG-OSBC, signifying that the adsorption of CLOF onto both adsorbents is physisorption. Moreover, the maximum adsorption capacity of OSBC is $149.30 \mathrm{mg} / \mathrm{g}$, which is aligned with Langmuir's maximum adsorption capacity.

\subsubsection{Kinetic Studies}

Four kinetic models were used to study the adsorption mechanism of CLOF onto both adsorbents, namely pseudo-first-order (PFO), pseudo-second-order (PSO), Elovich, and Weber-Morris (WM) models. The obtained data presented in Figure 11a,b show the relation between $q_{t}(\mathrm{mg} / \mathrm{g})$ versus time $(\mathrm{min})$ for the adsorption of CLOF onto OSBC and MAG-OSBC, respectively. Calculated parameters for the four models are shown in Table 7. The obtained data show that the $\mathrm{R}^{2}$ value is higher for the PSO model for both adsorbents ( 0.9416 for OSBC and 0.9224 for MAG-OSBC). These findings indicate that the rate of the adsorption reaction depends on both drug and adsorbent and that the reaction could be represented as follows, Equation (12):

$$
\mathrm{CLOF}+\mathrm{OSBC} \text { or MAG-OSBC }(\stackrel{k}{\rightarrow})\{\mathrm{CLOF}-\mathrm{OSBC}\} \text { or }\{\mathrm{CLOF}-\mathrm{MAG}-\mathrm{OSBC}\}
$$



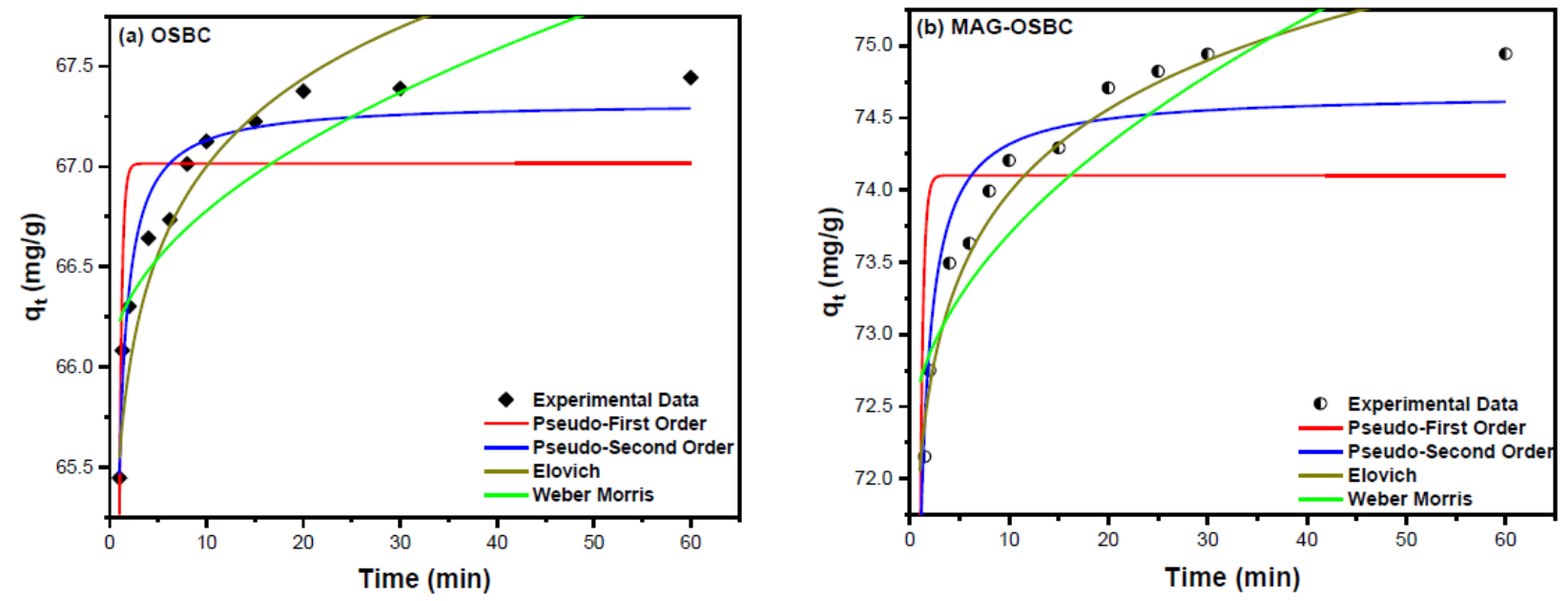

Figure 11. Kinetic models for the adsorption of CLOF onto (a) OSBC and (b) MAG-OSBC.

Table 7. Data for the kinetic studies corresponding to the data shown in Figure 11.

\begin{tabular}{|c|c|c|c|}
\hline \multirow{2}{*}{ Models } & \multirow{2}{*}{ Parameter } & \multicolumn{2}{|c|}{ Value } \\
\hline & & OSBC & MAG-OSBC \\
\hline \multirow{3}{*}{$\begin{array}{l}\text { Pseudo-first-order (PFO) } \\
\qquad \frac{d q_{t}}{d t}=k_{1}\left(q_{e}-q_{t}\right)\end{array}$} & $K_{1}\left(\min ^{-1}\right)$ & 3.644 & 3.236 \\
\hline & $q_{e}(\mathrm{mg} / \mathrm{g})$ & 67.01 & 74.10 \\
\hline & $R^{2}$ & 0.6725 & 0.5025 \\
\hline \multirow{3}{*}{$\begin{array}{l}\text { Pseudo-second-order (PSO) } \\
\qquad \frac{d q_{t}}{d t}=k_{2}\left(q_{e}-q_{t}\right)^{2}\end{array}$} & $K_{2}\left(\mathrm{~g} \cdot \mathrm{mg}^{-1} \cdot \mathrm{min}^{-1}\right)$ & 0.524 & 0.281 \\
\hline & $q_{e}(\mathrm{mg} / \mathrm{g})$ & 67.32 & 74.67 \\
\hline & $R^{2}$ & 0.9416 & 0.9224 \\
\hline \multirow{3}{*}{$\begin{array}{c}\text { Elovich model } \\
q_{t}=\frac{1}{\beta} \times \ln (1+\alpha \beta t)\end{array}$} & $\alpha$ & $8.28 \times 10^{44}$ & $2.08 \times 10^{37}$ \\
\hline & $B$ & 1.585 & 1.195 \\
\hline & $\mathrm{R}^{2}$ & 0.7761 & 0.9479 \\
\hline \multirow{3}{*}{$\begin{array}{l}\text { Weber-Morris model (WM) } \\
\qquad q_{t}=K_{I} t^{0.5}+C\end{array}$} & $K_{I}$ & 0.255 & 0.475 \\
\hline & C & 65.97 & 72.19 \\
\hline & $\mathrm{R}^{2}$ & 0.6789 & 0.7605 \\
\hline
\end{tabular}

where $K_{2}$ is rate constant $\left(\mathrm{g} \cdot \mathrm{mg}^{-1} \cdot \mathrm{min}^{-1}\right)$ and $q_{t}$ is adsorbed quantity at time $t$; while $\alpha$ and $\beta$ are initial sorption concentration rate $\left(\mathrm{mg} \cdot \mathrm{g}^{-1} \cdot \mathrm{min}^{-1}\right)$, and desorption constant $(\mathrm{g} / \mathrm{mg}), K_{I}$ is intraparticle diffusion rate constant $\left(\mathrm{mg} \cdot \mathrm{g}^{-1} \cdot \mathrm{min}^{-0.5}\right)$, and $C$ is boundary thickness effect.

In agreement with the literature, and as is shown in Table 1, the adsorption of PhACs and other organics on adsorbents derived from the olive stones followed a PSO kinetic model [31-35,37].

On the other hand, the Elovich model shows significant initial adsorption for both adsorbents, which equals $8.28 \times 10^{44} \mathrm{mg} \cdot \mathrm{g}^{-1} \cdot \mathrm{min}^{-1}$ for OSBC and $2.08 \times 10^{37} \mathrm{mg} \cdot \mathrm{g}^{-1} \cdot \mathrm{min}^{-1}$ for MAG-OSBC. Finally, the $\mathrm{R}^{2}$ value of the Weber-Morris (WM) was too small for both adsorbents compared to the other models (0.6789 and 0.7605 for OSB and MAG-OSBC, respectively); hence this model cannot be used to describe the adsorption of CLOF on the studied adsorbents.

\subsection{Desorption and Recovery Studies}

The economic usability for any adsorbent is a significant aspect, and it depends essentially on the adsorbent regeneration. For this purpose, a desorption study was performed using six different eluents, followed by consecutive adsorption-desorption cycles repeated for six cycles [65]. For the desorption study, six eluents were tested for the desorption of CLOF from OSBC and MAG-OSBC adsorbents, including $0.1 \mathrm{M}$ solutions of $\mathrm{HCl}, \mathrm{H}_{2} \mathrm{SO}_{4}, \mathrm{HNO}_{3}$, and $\mathrm{Na}_{2} \mathrm{CO}_{3}$, in addition to ethanol and $\mathrm{H}_{2} \mathrm{O}$. The data shown in 
Figure 12a present the relation between the tested eluents versus the desorption efficiency (\%). The obtained data show that ethanol is the best eluent for the desorption of CLOF from the OSBC, with a desorption efficiency of $81.56 \%$. On the other hand, the best eluent in the case of MAG-OSBC is $0.1 \mathrm{M} \mathrm{H}_{2} \mathrm{SO}_{4}$ with a desorption efficiency of $78.27 \%$. Accordingly, ethanol and $0.1 \mathrm{M} \mathrm{H}_{2} \mathrm{SO}_{4}$ were further used as the most suitable eluents for desorbing CLOF from OSBC and MAG-OSBC, respectively.
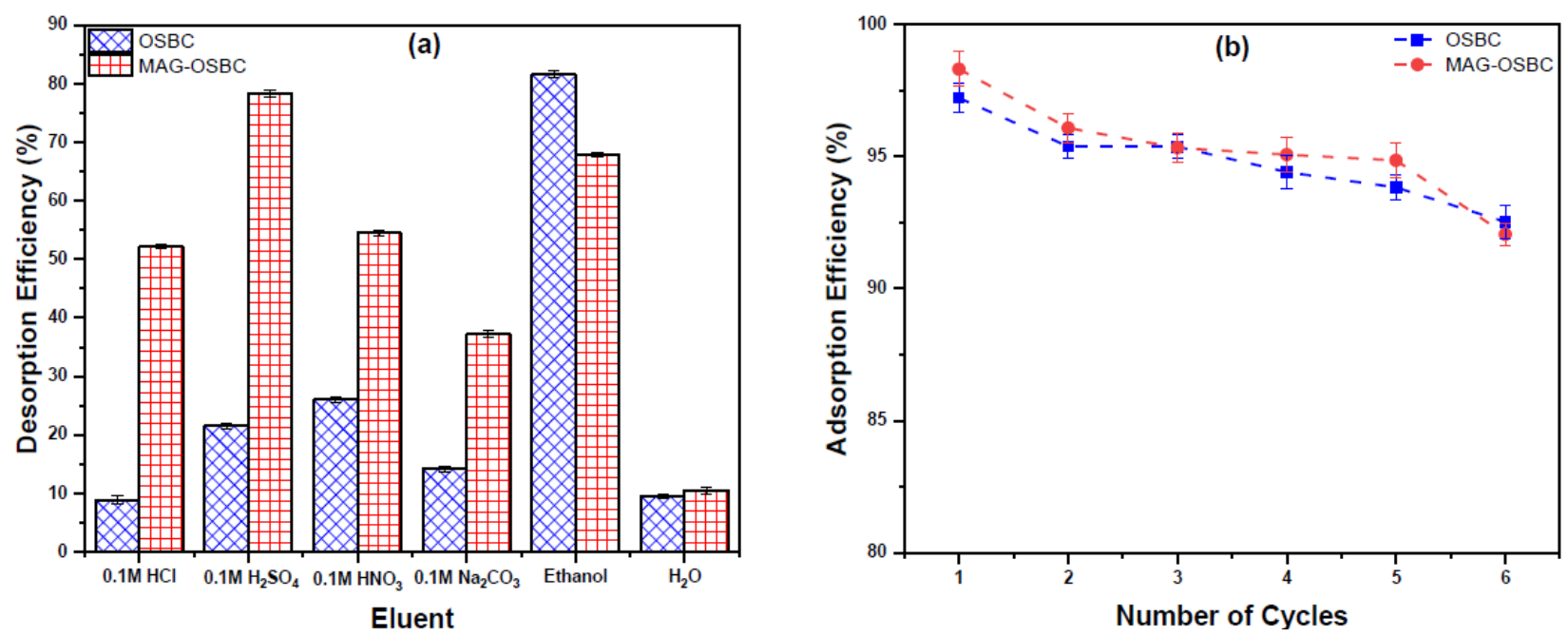

Figure 12. (a) Effect of eluent type on the CLOF desorption from OSBC, MAG-OSBC, and (b) the regeneration performance of both adsorbents for the CLOF removal.

For the adsorbent regeneration study, cyclic adsorption-desorption experiments were conducted, and the resulting data are shown in Figure 12b. The obtained data illustrate that CLOF removal efficiency decreased slightly for both adsorbents, whereas in the case of the OSBC, it decreased from $97.21 \%$ (cycle 1) to $92.52 \%$ (cycle 6), and for MAG-OSBC, it decreased from 98.31 (cycle 1) to $92.05 \%$ (cycle 6). These findings further confirm that both adsorbents are stable and can be regenerated successfully and used for more than six cycles with more than $90 \%$ CLOF removal efficiency.

\section{Conclusions}

According to the data presented, efficient and cost-effective adsorbents could be obtained by upcycling olive stones. Two adsorbents were successfully made and utilized in this study, the pristine biochar (OSBC) and the magnetic biochar (MAG-OSBC). Both adsorbents showed a high-efficiency and adsorptive power for clofazimine (CLOF), the widely consumed antituberculosis and antileprotic drug. The removal efficiency hit $98.61 \%$ using the MAG-OSBC, which is almost the same as the OSBC (98.10\%). TGA analysis showed that the presence of magnetic nanoparticles on the surface had enhanced the thermal stability of MAG-OSBC compared to the OSBC. Characterization of both adsorbents showed that their surfaces possess both meso- and macropores. MAG-OSBC showed a higher surface area $\left(33.82 \mathrm{~m}^{2} / \mathrm{g}\right)$ and pore volume $\left(0.166 \mathrm{~cm}^{3} / \mathrm{g}\right)$ than the OSBC. Furthermore, the FT-IR analysis before and after adsorption showed the changes in intensities and shifts in the position of some functional groups confirming the presence of CLOF on the adsorbents' surfaces. XRD data showed the presence of cubic $\mathrm{Fe}_{3} \mathrm{O}_{4}$ magnetic nanoparticles on the surface of the MAG-OSBC. A multivariate approach was utilized to optimize the dependent responses ( $\% \mathrm{R}$ and $q_{\mathrm{e}}$ ), employing Box-Behnken design as a platform. The objective was to achieve maximum removal of CLOF and the highest adsorption capacity of both adsorbents via the lowest possible consumption of chemicals and resources. Design analysis showed that $\mathrm{pH}$ plays a negligible role compared to the CT, AD and [CLOF]. Equilibrium studies using nonlinear fittings showed that data fit well to both Langmuir and Freundlich isotherms and that adsorption is favorable with a maximum adsorption 
capacity $\left(q_{\max }\right)$ of $174.03 \mathrm{mg} / \mathrm{g}$ in the case of MAG-OSBC compared to $137.90 \mathrm{mg} / \mathrm{g}$ using the OSBC. The adsorption was physisorption using both adsorbents. Investigation of adsorption kinetics showed that PSO perfectly fit the adsorption of CLOF onto either adsorbent. The desorption study showed that both adsorbents could be regenerated, with the adsorption efficiency being reserved up to $92 \%$ after six cycles. Consumption of materials and energy to produce $1 \mathrm{~kg}$ of the biochar showed that the current process is cost-effective and more economical than commercial adsorbents. While the OSBC is easy to prepare cost-effective adsorbent, there is difficulty in removing the powdered adsorbent, an issue that may lead to secondary pollution and could restrict its application on a large scale. The MAG-OSBC, however, and thanks to the magnetism, is separable and, therefore, could have wider scale applications. Yet, its cost-effectiveness and the probable environmental toxicity are issues that should be considered.

Author Contributions: Conceptualization: M.E.-A., A.S.E.-S. and S.S.H.; methodology: M.E.-A., I.N., S.S.H. and A.S.E.-S.; software: M.E.-A. and A.S.E.-S.; validation: M.E.-A., I.N. and A.S.E.-S.; formal analysis: M.E.-A., S.S.H. and A.S.E.-S.; investigation: A.S.E.-S. and M.E.-A.; resources: M.E.-A.; data curation: M.E.-A. and A.S.E.-S.; writing-original draft preparation: M.E.-A., I.N. and A.S.E.-S.; writing-review and editing: M.E.-A., A.S.E.-S. and I.N.; visualization: M.E.-A., S.S.H. and A.S.E.S.; supervision: M.E.-A.; project administration: M.E.-A.; funding acquisition: M.E.-A. and I.N. All authors have read and agreed to the published version of the manuscript.

Funding: This research was funded by Qatar University, Internal student grant number QUST-1CAS-2021-4. The findings achieved herein are solely the responsibility of the authors.

Institutional Review Board Statement: Not applicable.

Informed Consent Statement: Not applicable.

Data Availability Statement: The data presented in this study are available within this article. Further inquiries could be directed to the authors.

Acknowledgments: The project members would like to extend their special thanks to the Central Lab Unit (CLU) at Qatar University. The authors would also like to extend their gratitude to the lab members of Siham Alqaradawi's research group for accomplishing the BET analysis.

Conflicts of Interest: The authors declare no conflict of interest.

\section{References}

1. OECD 2019. Health at A Glance 2019: OECD Indicators; OECD Publishing: Paris, France, 2019. [CrossRef]

2. El-Gendy, A.; El-Shafie, A.S.; Issa, A.; Al-Meer, S.; Al-Saad, K.; El-Azazy, M. Carbon-Based Materials (CBMS) for Determination and Remediation of Antimicrobials in Different Substrates: Wastewater and Infant Foods as Examples. In Carbon-Based Material for Environmental Protection and Remediation; Bartoli, M., Frediani, M., Rosi, L., Eds.; IntechOpen: London, UK, 2020 ; pp. 103-122. [CrossRef]

3. Duan, L.; Zhang, Y.; Wang, B.; Cagnetta, G.; Deng, S.; Huang, J.; Wang, Y.; Yu, G. Characteristics of pharmaceutically active compounds in surface water in Beijing, China: Occurrence, spatial distribution and biennial variation from 2013 to 2017. Environ. Pollut. 2020, 264, 114753. [CrossRef] [PubMed]

4. World Health Organization. Multidrug and Extensively Drug Resistant Tuberculosis: 2010 Global Report on Surveillance and Response Geneva. Available online: https:/ / www.who.int/tb/publications/mdr_surveillance/en/ (accessed on 5 March 2021).

5. World Health Organization. World Health Organization Model List of Essential Medicines: 21st List 2019. Geneva. 2019. Available online: https:/ / apps.who.int/iris/handle/10665/325771 (accessed on 5 March 2021).

6. Ke, Y.Y.; Peng, T.T.; Yeh, T.K.; Huang, W.Z.; Chang, S.E.; Wu, S.H.; Hung, H.C.; Hsu, T.A.; Lee, S.J.; Song, J.S.; et al. Artificial intelligence approach fighting COVID-19 with repurposing drugs. Biomed. J. 2020, 43, 355-362. [CrossRef] [PubMed]

7. Wan, W.; Zhu, S.; Li, S.; Shang, W.; Zhang, R.; Li, H.; Liu, W.; Xiao, G.; Peng, K.; Zhang, L. High-throughput screening of an FDA-approved drug library identifies inhibitors against arenaviruses and SARS-CoV-2. ACS Infect. Dis. 2020. [CrossRef] [PubMed]

8. Stochino, C.; Villa, S.; Zucchi, P.; Parravicini, P.; Gori, A.; Raviglione, M.C. Clinical characteristics of COVID-19 and active tuberculosis co-infection in an Italian reference hospital. Eur. Respir J. 2020, 56, 2001708. [CrossRef]

9. Ateya, A.M. Clofazimine: A potential therapeutic option for severe COVID-19. Med. Hypotheses 2021, 110535. [CrossRef]

10. Murashov, M.D.; LaLone, V.; Rzeczycki, P.M.; Keswani, R.K.; Yoon, G.S.; Sud, S.; Rajeswaran, W.; Larsen, S.; Stringer, K.A.; Rosania, G.R. The physicochemical basis of Clofazimine-Induced skin pigmentation. J. Investig. Dermatol. 2018, 138, 697-703. [CrossRef] 
11. Zumla, A.I.; Gillespie, S.H.; Hoelscher, M.; Philips, P.P.; Cole, S.T.; Abubakar, I.; McHugh, T.D.; Schito, M.; Maeurer, M.; Nunn, A.J. New antituberculosis drugs, regimens, and adjunct therapies: Needs, advances, and future prospects. Lancet 2014, 14, 327-340. [CrossRef]

12. Somoskövi, A.; Bruderer, V.; Hömke, R.; Bloemberg, G.V.; Böttger, E.C. A mutation associated with clofazimine and bedaquiline cross-resistance in MDR-TB following bedaquiline treatment. Eur. Respir. J. 2015, 45, 554-557. [CrossRef]

13. El-Azazy, M.; El-Shafie, A.S.; El-Gendy, A.; Issa, A.; Al-Meer, S.; Al-Saad, K. A comparison between different agro-wastes and carbon nanotubes for removal of sarafloxacin from wastewater: Kinetics and equilibrium studies. Molecules 2020, $25,5429$. [CrossRef]

14. El-Azazy, M.; El-Shafie, A.S.; Al-Meer, S.; Al-Saad, K.A. Eco-Structured adsorptive removal of tigecycline from wastewater: Date pits' biochar versus the magnetic biochar. Nanomaterials 2021, 11, 30. [CrossRef]

15. Stets, S.; do Amaral, B.; Schneider, J.T.; de Barros, I.R.; de Liz, M.V.; Ribeiro, R.R.; Nagata, N.; Peralta-Zamora, P. Antituberculosis drugs degradation by UV-based advanced oxidation processes. J. Photochem. Photobiol. A 2018, 353, 26-33. [CrossRef]

16. Guelfi, D.R.V.; Gozzi, F.; Sirés, I.; Brillas, E.; Machulek, A., Jr.; de Oliveira, S.C. Antituberculosis drug isoniazid degraded by electro-Fenton and photoelectro-Fenton processes using a boron-doped diamond anode and a carbon-PTFE air-diffusion cathode. Environ. Sci. Pollut. Res. 2019, 26, 4415-4425. [CrossRef]

17. Xiang, Y.; Xu, Z.; Wei, Y.; Zhou, Y.; Yang, X.; Yang, Y.; Yang, J.; Zhang, J.; Luo, L.; Zhou, Z. Carbon-based materials as adsorbent for antibiotics removal: Mechanisms and influencing factors. J. Environ. Manag. 2019, 237, 128-138. [CrossRef]

18. Rathi, B.S.; Kumar, P.S.; Show, P.L. A review on effective removal of emerging contaminants from aqc uatic systems: Current trends and scope for further research. J. Hazard. Mater. 2021, 409, 124413. [CrossRef]

19. Rout, P.R.; Zhang, T.C.; Bhunia, P.; Surampalli, R.Y. Treatment technologies for emerging contaminants in wastewater treatment plants: A review. Sci. Total Environ. 2021, 753, 141990. [CrossRef]

20. Hassan, S.S.; El-Shafie, A.S.; Zaher, N.; El-Azazy, M. Application of pineapple leaves as adsorbents for removal of rose bengal from wastewater: Process optimization operating face-centered central composite design (FCCCD). Molecules 2020, $25,3752$. [CrossRef]

21. El-Azazy, M.; El-Shafie, A.S.; Ashraf, A.; Issa, A.A. Eco-structured biosorptive removal of basic fuchsin using pistachio nutshells: A definitive screening design—based approach. Appl. Sci. 2019, 9, 4855. [CrossRef]

22. El-Azazy, M.; Dimassi, S.; El-Shafie, A.S.; Issa, A. Bio-waste aloe vera leaves as an efficient adsorbent for titan yellow from wastewater: Structuring of a novel adsorbent using Plackett-Burman factorial design. Appl. Sci. 2019, 9, 4856. [CrossRef]

23. Al-Saad, K.; El-Azazy, M.; Issa, A.A.; Al-Yafie, A.; El-Shafie, A.S.; Al-Sulaiti, M.; Shomar, B. Recycling of date pits into a green adsorbent for removal of heavy metals: A Fractional Factorial Design-Based approach. Front. Chem. 2019, 7, 552. [CrossRef]

24. El-Azazy, M.; El-Shafie, A.S.; Issa, A.A.; Al-Sulaiti, M.; Al-Yafie, J.; Shomar, B.; Al-Saad, K. Potato peels as an adsorbent for heavy metals from aqueous solutions: Eco-structuring of a green adsorbent operating Plackett-Burman Design. J. Chem. 2019, 2019, 4926240. [CrossRef]

25. Yi, Y.; Huang, Z.; Lu, B.; Xian, J.; Tsang, E.P.; Cheng, W.; Fang, J.; Fang, Z. Magnetic biochar for environmental remediation: A review. Bioresour. Technol. 2020, 298, 122468. [CrossRef]

26. D'Cruz, B.; Madkour, M.; Amin, M.O.; Al-Hetlani, E. Efficient and recoverable magnetic $\mathrm{AC}_{-} \mathrm{Fe}_{3} \mathrm{O}_{4}$ nanocomposite for rapid removal of promazine from wastewater. Mater. Chem. Phys. 2020, 240, 122109. [CrossRef]

27. Liyanage, A.S.; Canaday, S.; Pittman, C.U., Jr.; Mlsna, T. Rapid remediation of pharmaceuticals from wastewater using magnetic $\mathrm{Fe}_{3} \mathrm{O}_{4}$ /Douglas fir biochar adsorbents. Chemosphere 2020, 258, 127336. [CrossRef]

28. Bhatnagar, A.; Kaczala, F.; Hogland, W.; Marques, M.; Paraskeva, C.A.; Papadakis, V.G.; Sillanpää, M. Valorization of solid waste products from the olive oil industry as potential adsorbents for water pollution control-A review. Environ. Sci. Pollut. Res. 2014, 21, 268-298. [CrossRef]

29. Corral-Bobadilla, M.; Lostado-Lorza, R.; Somovilla-Gómez, F.; Escribano-García, R. Effective use of activated carbon from olive stone waste in the biosorption removal of Fe(III) ions from aqueous solutions. J. Clean. Prod. 2021, 294, 126332. [CrossRef]

30. Eder, S.; Müller, K.; Azzari, P.; Arcifa, A.; Peydayesh, M.; Nyström, L. Mass transfer mechanism and equilibrium modelling of hydroxytyrosol adsorption on olive pit-derived activated carbon. Chem. Eng. J. 2021, 404, 126519. [CrossRef]

31. El Bakouri, H.; Usero, J.; Morillo, J.; Ouassini, A. Adsorptive features of acid-treated olive stones for drin pesticides: Equilibrium, kinetic and thermodynamic modeling studies. Bioresour. Technol. 2009, 100, 4147-4155. [CrossRef]

32. Hazzaa, R.; Hussein, M. Adsorption of cationic dye from aqueous solution onto activated carbon prepared from olive stones. Environ. Technol. Innov. 2015, 4, 36-51. [CrossRef]

33. Uğurlu, M.; Gürses, A.; Açıkyıldız, M. Comparison of textile dyeing effluent adsorption on commercial activated carbon and activated carbon prepared from olive stone by $\mathrm{ZnCl}_{2}$ activation. Microporous Mesoporous Mater. 2008, 111, 228-235. [CrossRef]

34. Albadarin, A.B.; Mangwandi, C. Mechanisms of alizarin red s and methylene blue biosorption onto olive stone by-product: Isotherm study in single and binary systems. J. Environ. Manag. 2015, 164, 86-93. [CrossRef]

35. Jafari, K.; Heidari, M.; Rahmanian, O. Wastewater treatment for amoxicillin removal using magnetic adsorbent synthesized by ultrasound process. Ultrason. Sonochem. 2018, 45, 248-256. [CrossRef] [PubMed]

36. García-Mateos, F.J.; Ruiz-Rosas, R.; Marqués, M.D.; Cotoruelo, L.M.; Rodríguez-Mirasol, J.; Cordero, T. Removal of paracetamol on biomass-derived activated carbon: Modeling the fixed bed breakthrough curves using batch adsorption experiments. Chem. Eng. J. 2015, 279, 18-30. [CrossRef] 
37. Larous, S.; Meniai, A.-H. Adsorption of diclofenac from aqueous solution using activated carbon prepared from olive stones. Int. J. Hydrog. Energy 2016, 41, 10380-10390. [CrossRef]

38. El-Azazy, M.; Kalla, R.N.; Issa, A.A.; Al-Sulaiti, M.; El-Shafie, A.S.; Shomar, B.; Al-Saad, K. Pomegranate peels as versatile adsorbents for water purification: Application of Box-Behnken Design as a methodological optimization approach. Environ. Prog. Sustain. Energy 2019, 38, 13223. [CrossRef]

39. Elazazy, M.S. Factorial Design and Machine Learning Strategies: Impacts on Pharmaceutical Analysis. In Spectroscopic Analyses; Zafar, F., Ed.; IntechOpen: London, UK, 2017; pp. 213-230. Available online: https://www.intechopen.com/ books/spectroscopic-analyses-developments-and-applications/factorial-design-and-machine-learning-strategies-impacts-onpharmaceuticalanalysis (accessed on 30 October 2020). [CrossRef]

40. Karunanayake, A.G.; Todd, O.A.; Crowley, M.L.; Ricchetti, L.B.; Pittman, C.U., Jr.; Anderson, R.; Mlsna, T.E. Rapid removal of salicylic acid, 4-Nitroaniline, benzoic acid and phthalic acid from wastewater using magnetized fast pyrolysis biochar from waste douglas Fir. Chem. Eng. J. 2017, 319, 75-88. [CrossRef]

41. Bagheri, A.R.; Ghaedi, M.; Asfaram, A.; Bazrafshan, A.A.; Jannesar, R. Comparative study on ultrasonic assisted adsorption of dyes from single system onto $\mathrm{Fe}_{3} \mathrm{O}_{4}$ magnetite nanoparticles loaded on activated carbon: Experimental design methodology. Ultrason. Sonochem. 2017, 34, 294-304. [CrossRef]

42. Shahrashoub, M.; Bakhtiari, S. The efficiency of activated carbon/magnetite nanoparticles composites in copper removal: Industrial waste recovery, green synthesis, characterization, and adsorption-desorption studies. Microporous Mesoporous Mater. 2021, 311, 110692. [CrossRef]

43. Rahmani, R.; Gharanfoli, M.; Gholamin, M.; Darroudi, M.; Chamani, J.; Sadri, K. Green synthesis of ${ }^{99 m} \mathrm{Tc}^{-1 a b e l e d-F e} \mathrm{O}_{4}$ nanoparticles using Quince seeds extract and evaluation of their cytotoxicity and biodistribution in rats. J. Mol. Struct. 2019, 1196, 394-402. [CrossRef]

44. Abdelhadi, S.O.; Dosoretz, C.G.; Rytwo, G.; Gerchman, Y.; Azaizeh, H. Production of biochar from olive mill solid waste for heavy metal removal. Bioresour Technol. 2017, 244, 759-767. [CrossRef]

45. Bolla, G.; Nangia, A. Clofazimine mesylate: A high solubility stable salt. Cryst. Growth Des. 2012, 12, 6250-6259. [CrossRef]

46. Chaves, L.L.; Lima, S.; Vieira, A.C.C.; Ferreira, D.; Sarmento, B.; Reis, S. Overcoming clofazimine intrinsic toxicity: Statistical modelling and characterization of solid lipid nanoparticles. J. R. Soc. Interface 2018, 15, 20170932. [CrossRef]

47. Moubarik, A.; Grimi, N. Valorization of olive stone and sugar cane bagasse by-products as biosorbents for the removal of cadmium from aqueous solution. Food Res. Int. 2015, 73, 169-175. [CrossRef]

48. Blázquez, G.; Martín-Lara, M.A.; Dionisio-Ruiz, E.; Tenorio, G.; Calero, M. Evaluation and comparison of the biosorption process of copper ions onto olive stone and pine bark. J. Ind. Eng. Chem. 2011, 17, 824-833. [CrossRef]

49. Guo, C.; Hu, Y.; Qian, H.; Ning, J.; Xu, S. Magnetite $\left(\mathrm{Fe}_{3} \mathrm{O}_{4}\right)$ tetrakaidekahedral microcrystals: Synthesis, characterization, and micro-Raman study. Mater. Charact. 2011, 62, 148-151. [CrossRef]

50. De Faria, D.L.A.; Lopes, F.N. Heated goethite and natural hematite: Can raman spectroscopy be used to differentiate them? Vib. Spectrosc. 2007, 45, 117-121. [CrossRef]

51. Ivashchenko, O.; Jurga-Stopa, J.; Coy, E.; Peplinska, B.; Pietralik, Z.; Jurga, S. Fourier transform infrared and Raman spectroscopy studies on magnetite/Ag/antibiotic nanocomposites. Appl. Surf. Sci. 2016, 364, 400-409. [CrossRef]

52. Buttersack, C. Modeling of type IV and V sigmoidal adsorption isotherms. Phys. Chem. Chem. Phys. 2019, 21, 5614-5626. [CrossRef]

53. Anyika, C.; Asri, N.A.M.; Majid, Z.A.; Yahya, A.; Jaafar, J. Synthesis and characterization of magnetic activated carbon developed from palm kernel shells. Nanotechnol. Environ. Eng. 2017, 2, 1-25. [CrossRef]

54. Castro, C.S.; Guerreiro, M.C.; Gonçalves, M.; Oliveira, L.C.A.; Anastácio, A.S. Activated carbon/iron oxide composites for the removal of atrazine from aqueous medium. J. Hazard. Mater. 2009, 164, 609-614. [CrossRef]

55. Kahani, S.A.; Hamadanian, M.; Vandadi, O. Deposition of magnetite nanoparticles in activated carbons and preparation of magnetic activated carbons. AIP Conf. Proc. 2007, 929, 183-188. [CrossRef]

56. Box, G.E.; Behnken, D.W. Some new three level designs for the Study of quantitative variables. Technometrics 1960, 2, 455-475. [CrossRef]

57. Elmasry, M.S.; Elazazy, M.S.; El-Sayed, H.M. Multivariate analysis of tioconazole-TCNQ charge transfer interaction: Kinetics, thermodynamics and twofold response optimization. Spectrochim. Acta A Mol. Biomol. Spectrosc. 2018, 202, 401-409. [CrossRef]

58. Derringer, G.; Suich, R. Simultaneous optimization of several response variables. J. Qual. Technol. 1980, 12, 214-219. [CrossRef]

59. Langmuir, I. Adsorption of gases on glass, mica and platinum. J. Am. Chem. Soc. 1918, 40, 1361-1403. [CrossRef]

60. Guo, X.; Wang, J. Comparison of linearization methods for modeling the Langmuir adsorption isotherm. J. Mol. Liq. 2019, 296, 111850. [CrossRef]

61. Araújo, C.S.T.; Almeida, I.L.S.; Rezende, H.C.; Marcionilio, S.M.L.O.; Léon, J.J.L.; de Matos, T.N. Elucidation of mechanism involved in adsorption of $\mathrm{Pb}$ (II) onto Lobeira fruit (Solanum lycocarpum) using Langmuir, Freundlich and Temkin isotherms. Microchem. J. 2018, 137, 348-354. [CrossRef]

62. Moussavi, G.; Barikbin, B. Biosorption of chromium (VI) from industrial wastewater onto pistachio hull waste biomass. Chem. Eng. J. 2010, 162, 893-900. [CrossRef] 
63. Salvestrini, S.; Fenti, A.; Chianese, S.; Iovino, P.; Musmarra, D. Diclofenac sorption from synthetic water: Kinetic and thermodynamic analysis. J. Environ. Chem. Eng. 2020, 8, 104105. [CrossRef]

64. Vafaei, A.; Ghaedi, A.M.; Avazzadeh, Z.; Kiarostami, V.; Agarwal, S.; Gupta, V.K. Removal of hydrochlorothiazide from molecular liquids using carbon nanotubes: Radial basis function neural network modeling and culture algorithm optimization. J. Mol. Liq. 2021, 324, 114766. [CrossRef]

65. Singh, T.; Singhal, R. Methyl orange adsorption by reuse of a waste adsorbent poly(AAc/AM/SH)-MB superabsorbent hydrogel: Matrix effects, adsorption thermodynamic and kinetics studies. Desalination Water Treat. 2015, 53, 1942-1956. [CrossRef] 